This is an Accepted Manuscript of an article published by Taylor \& Francis in Mechanics of Advanced Materials and Structures on 29/10/18, available online: https://www.tandfonline.com/doi/

abs/10.1080/15376494.2018.1525628?journalCode=umcm20

\title{
Experimental Investigation of Quasi-Static Penetration Tests on Honeycomb Sandwich Panels Filled with Polymer Foam
}

\author{
Fatemeh Hassanpour Roudbeneh ${ }^{1}$, Gholamhossein Liaghat ${ }^{1,2^{*}}$, Hadi Sabouri ${ }^{3}$, \\ Homayoun Hadavinia ${ }^{2}$ \\ ${ }^{1}$ Department of Mechanical Engineering, Tarbiat Modares University, Tehran, Iran \\ ${ }^{2}$ School of Engineering, Kingston University, London, SW 15 3DW, UK \\ ${ }^{3}$ Department of Mechanical Engineering, Faculty of Engineering, Kharazmi University, Tehran, Iran \\ * Corresponding author, Ghlia530@ modares.ac.ir and Gholamhossein.Liaghat@kingston.ac.uk
}

\begin{abstract}
In this paper, the quasi-static penetration tests were investigated on unfilled and polyurethane foam filled honeycomb sandwich panels. Failure mechanisms, specific energy absorption, interaction mechanisms and some structural responses were studied. Comparing the three types of the foam filled sandwich panels with unfilled type, indicates that the absorbed energy of the first, second and third type of the panels are $23 \%, 33 \%$ and $58 \%$ more than unfilled ones, respectively. In addition, the results showed the enhancement in the dynamic strength and
\end{abstract}


remarkably decrease in the damage area of the sandwich structure when its honeycomb core was filled with polymer foam.

Keywords: Sandwich panel, Honeycomb core, Polyurethane foam, Quasi-static penetration, Interaction mechanism, Specific energy absorption

\section{Nomenclature}

E $\quad$ Elastic modulus (GPa)

$\mathrm{E}_{\mathrm{c}} \quad$ Compressive modulus of the foam $(\mathrm{kPa})$

SEA Specific energy absorption $(\mathrm{J} / \mathrm{kg})$

$\varepsilon_{\mathrm{d}} \quad$ Densification strain

$\varepsilon_{\mathrm{u}} \quad$ Failure strain

V Poisson ratio

$\rho \quad$ Density $\left(\mathrm{kg} / \mathrm{m}^{3}\right)$

$\sigma_{\mathrm{c}} \quad$ Compressive stress of the foam $(\mathrm{kPa})$

$\sigma_{\mathrm{d}} \quad$ Densification stress $(\mathrm{MPa})$

$\sigma_{\mathrm{u}} \quad$ Ultimate tensile strength (MPa)

$\sigma_{\mathrm{y}} \quad$ Yield strength $(\mathrm{MPa})$

$\tau_{\mathrm{u}} \quad$ Ultimate shear strength (MPa) 


\section{Introduction}

Due to the increasing development in marine industry, automotive, transportation and aeronautics engineering, evaluating the absorbing energy capacity of structures has been considered as an important field of research [1]. During the last decade, high specific absorbing energy materials and structures such as thin metal structures have been investigated which the graded honeycomb is an example of these structures [2]. Honeycombs are produced from metallic or polymeric substances. Their cells have various size and shape; however, they are often hexagonal [3]. Due to the promising properties of these structures, at first, many experiments have been performed on single honeycomb structures in order to study their response to various static and dynamic loadings and also the effect of their parameters such as cell size, their constructions, and etc. on the amount of energy absorption under distributed loading. For instance, Goldsmith and Louie [4] studied on aluminum honeycombs axial perforation with highlighting spherical strikers which causes more in-plane damage under both quasi-static and ballistic conditions. Galehdari et al. [5] studied the graded honeycomb structure (GHS) behavior under in-plane impact loading with low velocity and its optimization via analytical, experimental, and numerical methods. They compared the time period of reaction force of two graded honeycomb structures with equal thickness and also investigated the effect of power hardening model for the graded honeycomb structure (GHS) material on the plateau stress. Papka and Kyriakides [6, 7] investigated the load-displacement response of hexagonalcell aluminum honeycombs and circular polycarbonate honeycombs subjected to in-plane uniaxial loading. They detected various deformation modes related to the particular ratio between the parts of the applied displacements or forces. Alavi Nia et al. [8] and Liaghat et al. [9] put forward a determination method for the ballistic limit velocity of metallic honeycombs under 
high velocity loading conditions. Several other studies have been conducted to evaluate the outof-plane performance of these structures subjected to both quasi-static and dynamic loadings. The results demonstrated a remarkable improvement in dynamic plateau stress in comparison with their analogous subjected to static loadings (up to 70\%) [10-15].

In the next step, many attempts have been made to increase the strength of the honeycomb structures by using them as sandwich panels. Sandwich structures consist of 1) a pair of thin stiff, strong skins (faces, facings or covers); 2) a thick, lightweight core to separate the skins and carry loads from one skin to the other; and 3) an adhesive attachment which is capable of transmitting shear and axial loads to and from the core [16]. The same as the single honeycomb structures, honeycomb core sandwich panels received a great deal of attention to be used in many industrial fields because of their high strength to weight ratio and perfect energy absorption properties [17]. However, they faced many new challenges to be used rapidly because the mechanical behaviors, failure modes, energy absorption capacity, and other serious issues of honeycomb sandwich panels are highly affected by the loading conditions and needs a considerable investigations [18]. Therefore, numerous studies were conducted to explore these structures' behavior under various conditions. In the case of penetration experiments, there are different types of tests such as quasistatic loading, low-velocity impact, high-velocity impact, and blast loading which are of great importance for the illustration of honeycomb sandwich panels' behavior. For example, Turk and Hoo Fatt [19] derived the closed-form solutions for the composite sandwich plate deformation and fracture responses under static indentation of a hemispherical-nose penetrator. They also proposed an estimated solution for the load-penetration response of the intended composite sandwich plates. Lolive and Berthelot [20] studied the sandwich panels with PVC (polyvinyl chloride) core with two densities and E-glass laminate face sheets subjected to quasi-static 
indentation test utilizing flat ended indenters with different diameters. They found that increasing the core density and also the indenter diameter results in the growth of indentation load. FloresJohnson and $\mathrm{Li}$ [21] conducted the experimental research on the quasi-static indentation of sandwich panels with carbon fiber-reinforced polymer face sheet and polymeric foam cores using stiff indenter. They observed that the nose shape and foam core density had a large influence on the indentation behavior of the sandwich panels. Moreover, they identified connection of the indentation load with the supporting state. Williamson [22] experimentally studied the static indentation and impact behavior of composite sandwich plates experimentally. They measured the failure area of face sheet under the indenter and also investigated the destructions of core and face sheet with different core thickness and laminate lay up. They identified the similarity between the load- defeat features and sandwich plates destruction predictions subjected to static indentation and low velocity impact experiments. Ruan et al. [23] studied the mechanical behavior and energy absorption of aluminum foam sandwich panels under quasi-static indentation loads experimentally. They investigated the effects of face sheet thickness, core thickness, boundary conditions, surface and adhesive conditions of face sheets on the mechanical properties of sandwich panels and energy absorption. Arslan et al. [24] determined the ballistic impact response of a new sandwich structure including aluminum honeycomb and $\mathrm{A} 1 / \mathrm{SiC}$ functionally graded face sheets and developed an appropriate numerical model with experiments. They found that the ceramic fraction of the functionally graded face sheets was relatively effective on energy absorption capability, damage mechanism, and impact resistance of the sandwich structure.

The mentioned articles are just a small part of the existed experimental and numerical studies which explores the behavior of sandwich panel structures under different loading conditions. 
This is just because of the vast number of various sandwich panels, different loading conditions, and especially the importance of understanding these structures' behavior for many industrial applications. It is worth mentioning that in all previous studies related to the penetration test, the core is built of foams or honeycombs alone. However, for increasing the resistance of the honeycomb core, some specific lightweight materials could be used to fill them such as different kinds of foams [25-27]. Among them, flexible polyurethane foam is widely utilized in numerous applications, including civil engineering, automotive, packaging, and personal protection, and so on because of its low cost, low weight, admirable performance in thermal insulation, acoustic absorption, and energy management [28-31].

Therefore, filling the aluminum honeycomb cores with polyurethane foam can be resulted in a structure which will simultaneously benefit the properties of these two components. To the best of our knowledge, no studies have been performed about experimental investigation of quasistatic penetration tests on honeycomb sandwich panels filled with polyurethane foam. As was clearly mentioned, the importance of lightweight structures especially honeycomb sandwich panels and their behavior under penetration loading is undeniable for many industries, therefore, in this paper, the quasi-static response of the unfilled and foam filled honeycomb core sandwich panels and their individual components is investigated to introduce a structure with higher energy absorption and lower cost than have been proposed up to now. To do have a more comprehensive view of these structures' behavior, the effects of interaction among aluminum skins, honeycomb structure, and the polyurethane foam on destruction shape, energy absorption, and specific absorbed energy are also demonstrated. 


\section{Experimental procedure}

\subsection{Materials}

In this research, sandwich structures are made from aluminum skins, unfilled or polyurethane foam filled honeycomb core, and epoxy resin for bonding the skins to the core. The aluminum skin was selected from grade 1200 with $0.5 \mathrm{~mm}$ thickness supplied by Arak Aluminum Company. The mechanical properties of the aluminum sheet, which were tested according to the ASTM E8M-04 standard [32], are shown in Table 1. The honeycomb structure was fabricated from 5052-H38 aluminum by corrugation process which its mechanical properties [33] and unit cell geometry are shown in Table 1 and Figure 1, respectively. Commercially available closedcell polyurethane foams (SKC501, SCC500) were used in this study. They are generally made of two organic units including Isocyanate and Polyol groups. Therefore, by mixing various percentages of them (Table 1), three types of weak, medium and strong foams were produced.

Since these foams were synthetic and were used in the core of sandwich structures that can change its behavior, their properties should be determined according to standard tests. The apparent density of each types of polyurethane foam were determined 56.94, 108.65 and 137.13

$\mathrm{kg} / \mathrm{m}^{3}$, based on ASTM D1622 standard [34]. Moreover, static compressive tests were performed according to ASTM D1621 standard [35] using a Universal Testing Machine (model WDW$300 \mathrm{E})$ at displacement rate of $2 \mathrm{~mm} / \mathrm{min}$. The size of specimens was $30 \times 30 \times 30 \mathrm{~mm}^{3}$. Five samples were prepared for each density and tested. Figure 2 shows the stress-strain curves for three types of foams. The compressive stress of the foam $\left(\sigma_{c}\right)$ and compressive modulus of the foam $\left(\mathrm{E}_{\mathrm{c}}\right)$ are summarized in Table 1. As shown in Table 1, the compressive test results showed 
that foam 3 had the most elastic modulus, and it was 2.5 and 5 times more than foam 2 and foam1, respectively.

Finally, the epoxy resin used for bonding face sheets and honeycomb cores was supplied by Shell Company, composed of CY-219 epoxy and HY-516 hardner with a mixing ratio of 2:1.

Table 1. The properties of material

\begin{tabular}{ccccccc}
\hline Material & \multicolumn{7}{c}{ Properties } \\
\hline $\begin{array}{c}\text { Honeycomb } \\
(5052-\mathrm{H3})\end{array}$ & $\rho\left(\mathrm{kg} / \mathrm{m}^{3}\right)$ & $\mathrm{E}(\mathrm{GPa})$ & $\sigma_{\mathrm{y}}(\mathrm{MPa})$ & $\sigma_{\mathrm{u}}(\mathrm{MPa})$ & $\tau_{\mathrm{u}}(\mathrm{MPa})$ & $\mathrm{V}$ \\
\cline { 2 - 6 } & 2680 & 70 & 255 & 290 & 165 & 0.3 \\
\hline \multirow{2}{*}{ Al plate } & $\rho\left(\mathrm{kg} / \mathrm{m}^{3}\right)$ & $\mathrm{E}(\mathrm{GPa})$ & $\sigma_{\mathrm{y}}(\mathrm{MPa})$ & $\sigma_{\mathrm{u}}(\mathrm{MPa})$ & $\varepsilon_{\mathrm{u}}$ & $*$ \\
\cline { 2 - 7 } & 2637 & 76 & 131 & 133 & 0.08 & $*$ \\
\hline PU foam 1 & 56.94 & 4 & 352 & $50 / 50$ & SKC501 & $*$ \\
\hline PU foam 2 & 108.65 & 8 & 864 & $75 / 25$ & SCC500 & $*$ \\
\hline PU foam 3 & 137.13 & 20 & 1553 & $75 / 25$ & SKC501 & $*$ \\
\hline
\end{tabular}

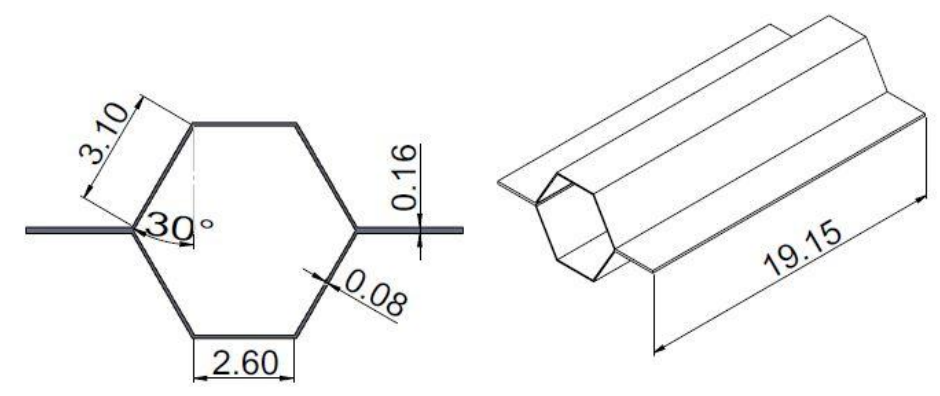

Figure 1. The geometry and dimensions of a honeycomb cell (all dimensions are in $\mathrm{mm}$ ) 


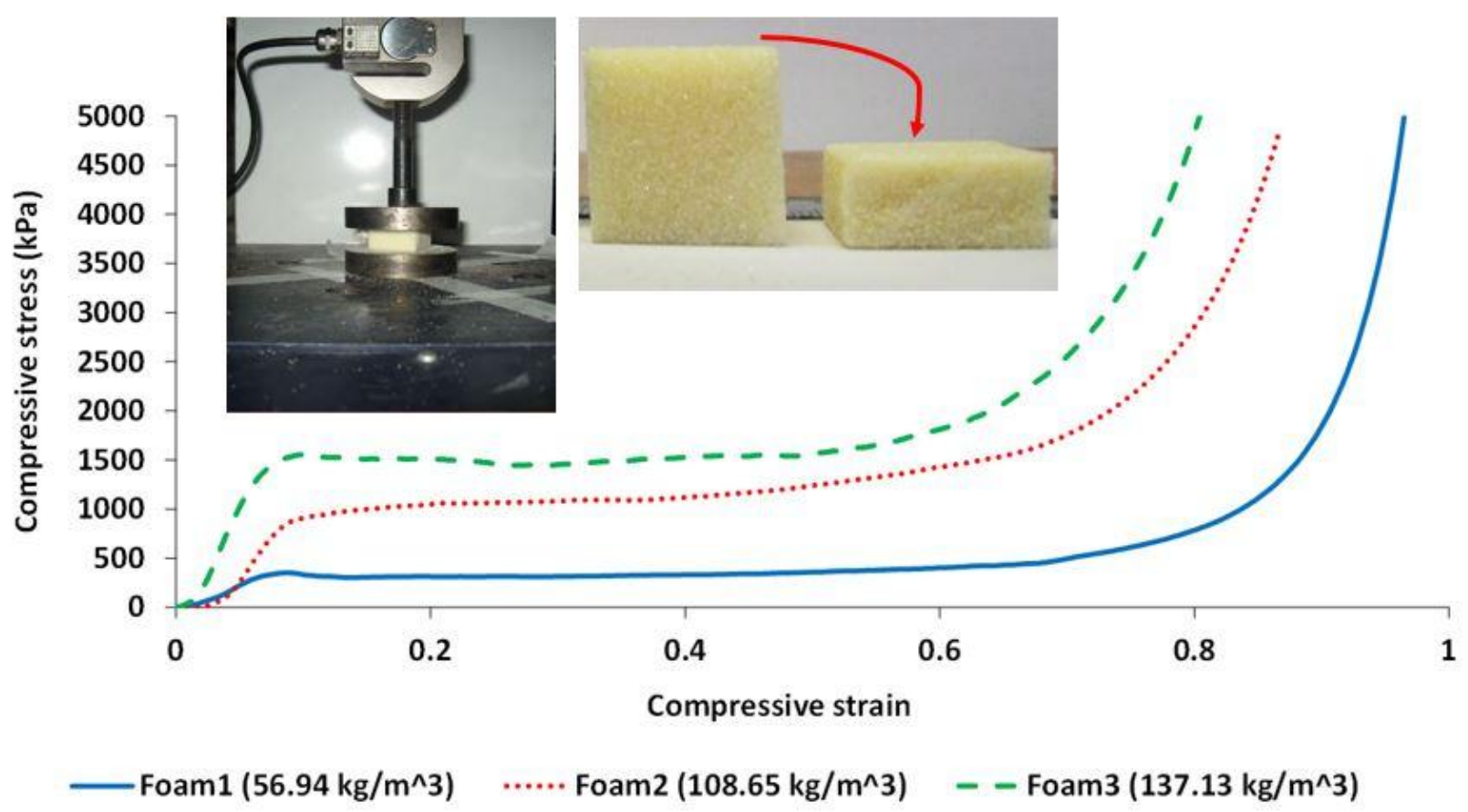

Figure 2. The stress-strain behaviors of the three types of foam from static compressive test

\subsection{Preparation of sandwich panel specimens}

The surface area of honeycomb structures was chosen at $75 \times 75 \mathrm{~mm}^{2}$ to fit the fixture span size. The cutting of specimens could not be done in a normal way because the walls of unfilled honeycomb were crumpling. The solution was to fill the honeycomb structures with water and freeze it. Then frozen honeycombs were cut to desirable pieces. After cutting the honeycomb, they should be filled with foam. For filling the honeycomb cells, a laminated plastic cast with dimensions $0.5 \mathrm{~cm}$ larger than the honeycomb samples size was made. Then, the Isocyanate and Polyol components were mixed with an electric blender and poured into the laminated plastic cast. After 60 seconds, the honeycomb was placed in the cast and hold down by putting a $300 \mathrm{~g}$ weight on it. Afterward, solidification of foam occurred and the honeycomb cells were filled. 
Then, the extra foams around the samples were removed. Finally, the sandwich structures were made by cutting the aluminum skin to pieces with an area of $75 \times 75 \mathrm{~mm}^{2}$ and these skins were bonded to unfilled/foam filled honeycomb cores using epoxy resin (Figure 3).

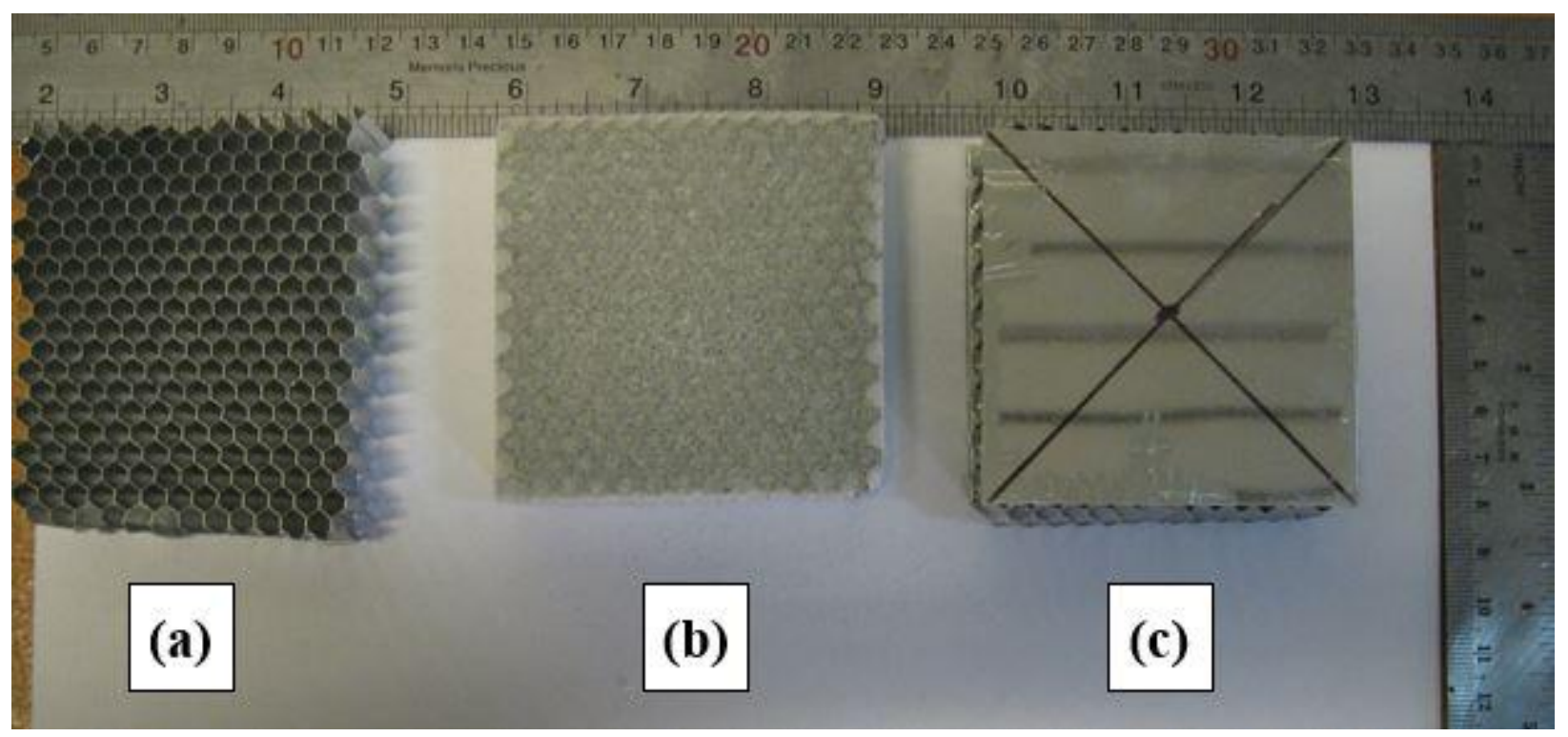

Figure 3. (a) Unfilled honeycomb structure, (b) foam filled honeycomb structure, and (c) sandwich panel specimens

\subsection{Quasi-static penetration tests}

Quasi-static indentation tests were performed on unfilled and foam filled sandwich panels by flat-ended indenter with $10 \mathrm{~mm}$ diameter and $1200 \mathrm{MPa}$ yield strength. Experiments were conducted using a Universal Testing Machine (model WDW-300E). The specimens were put in the fixture which its framed supporting plate had a window with dimensions of $50 \times 50 \mathrm{~mm}^{2}$ allowing deformation of the specimens during indentation experiment. The fixture was clamped 
by eight M16 bolts and nuts. Also, two M8 bolts were used to fasten the fixture to the Universal Testing Machine (model WDW-300E) for preventing slippage (locking the fixture) (Figure 4). The indenters were penetrated into the sandwich panels at displacement rate of $2 \mathrm{~mm} / \mathrm{min}$ in all samples. The contact force and displacement of the indenter were automatically recorded by a computer connected to the universal testing machine.
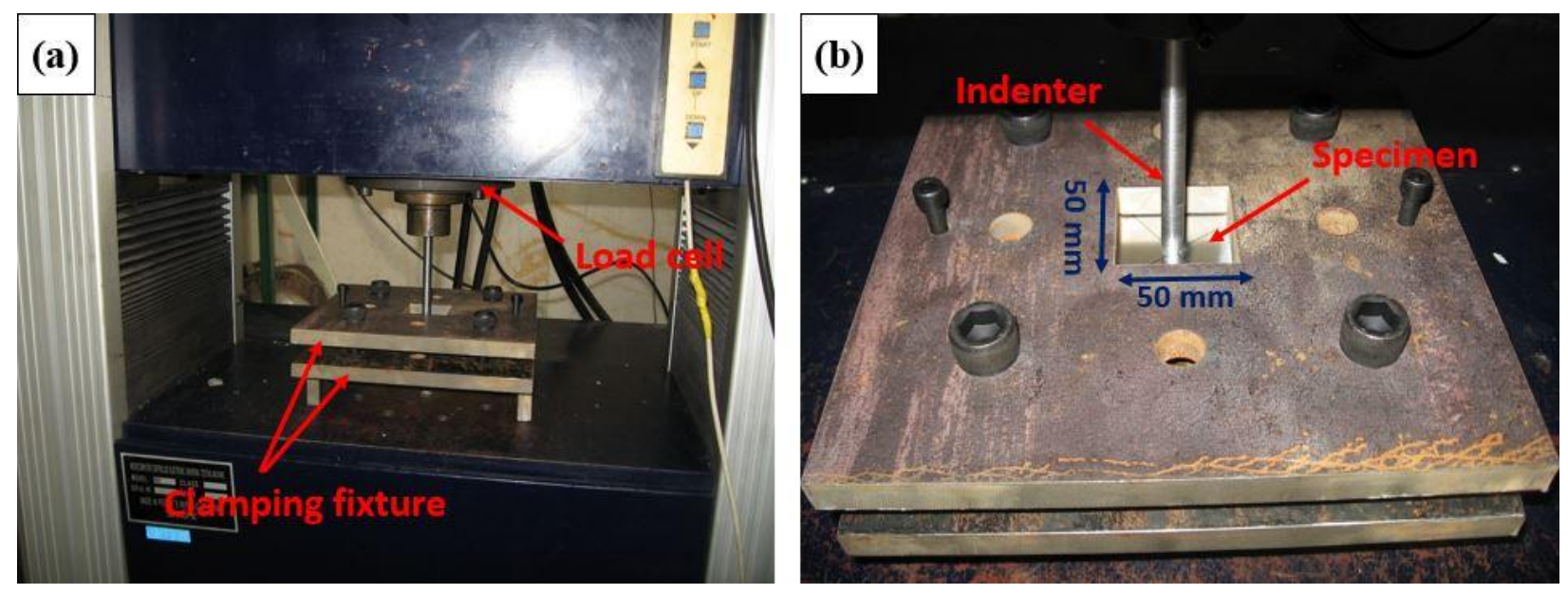

Figure 4. (a) Fixture installation on Universal Testing Machine, and (b) fixture, indenter and specimen

\section{Results and discussion}

The results of quasi-static penetration test on 1200 aluminum plate, unfilled honeycomb structure, honeycomb structure filled with three types of foam, sandwich panels with unfilled honeycomb core and filled with three types of foam; are described in the following sections.

\subsection{The analyses of destruction response under quasi-static penetration test}

After punching the aluminum plate, since the indenter was rigid in comparison to aluminum plate, a shear plug was formed equal to the indenter diameter (Figure 5). 
The load-penetration response curve of aluminum plate is shown in Figure 6. This curve can be divided into three parts, including the contact moment of penetrator, the duration of its passing through the specimen and finally the exit moment. The AB section in this diagram is related to the moment of indenter landing on the specimen. The BC section shows the increasing stiffness of the specimen while the penetrator is driving in to it. At $\mathrm{C}$ point the penetrator has perforated the aluminum sheet which is corresponding to maximum load carrying capacity of the aluminum plate. The vertical degradation of the curve after $\mathrm{C}$, predicates on sudden shear of the aluminum plate and rapid reduction of the indenting force. The CD section of indentation curve shows that the penetrator has exited from sheet and the slipping taken place between the lateral area of penetrator and the edge of hole, resulting downward proceeding of the curve because of decreasing friction factor between sliding areas.
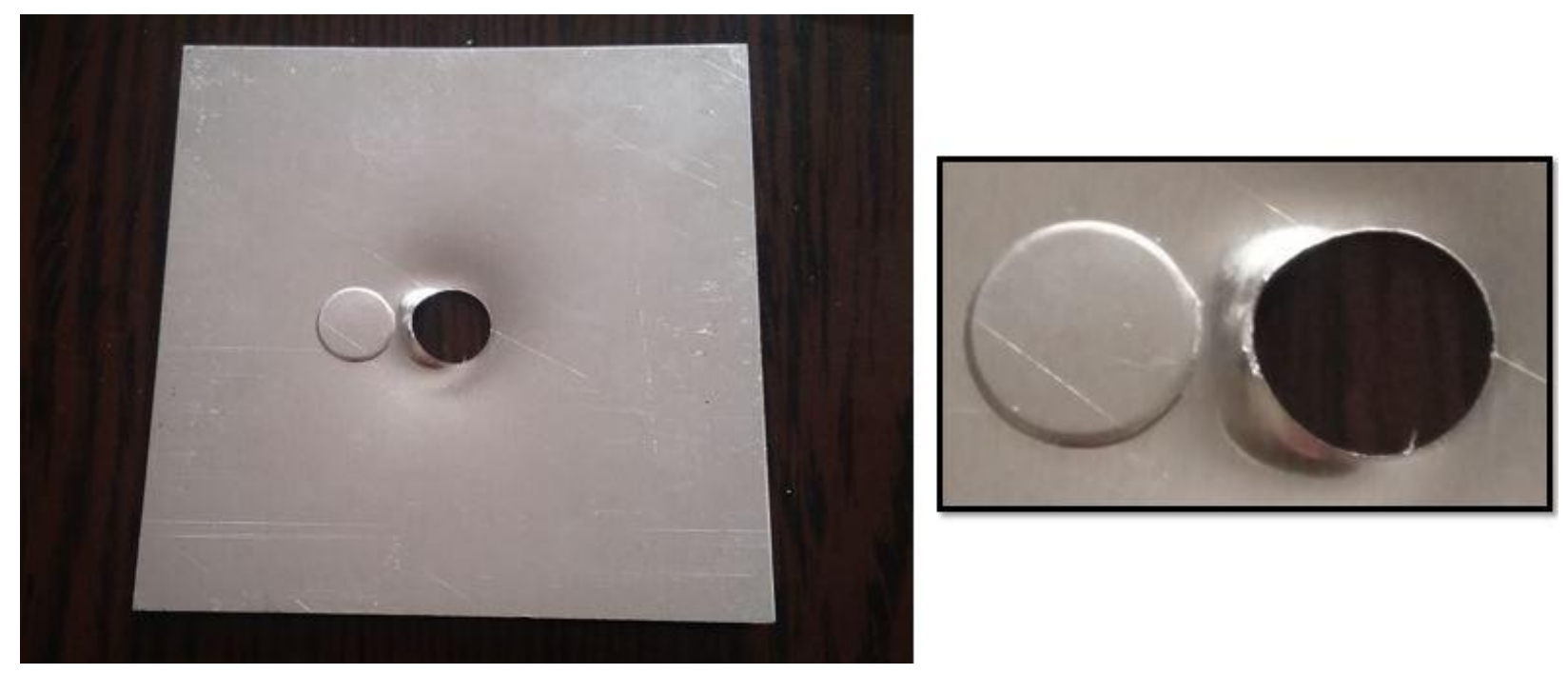

Figure 5. The backside of aluminum plate, after the quasi-static penetration and shear plug 


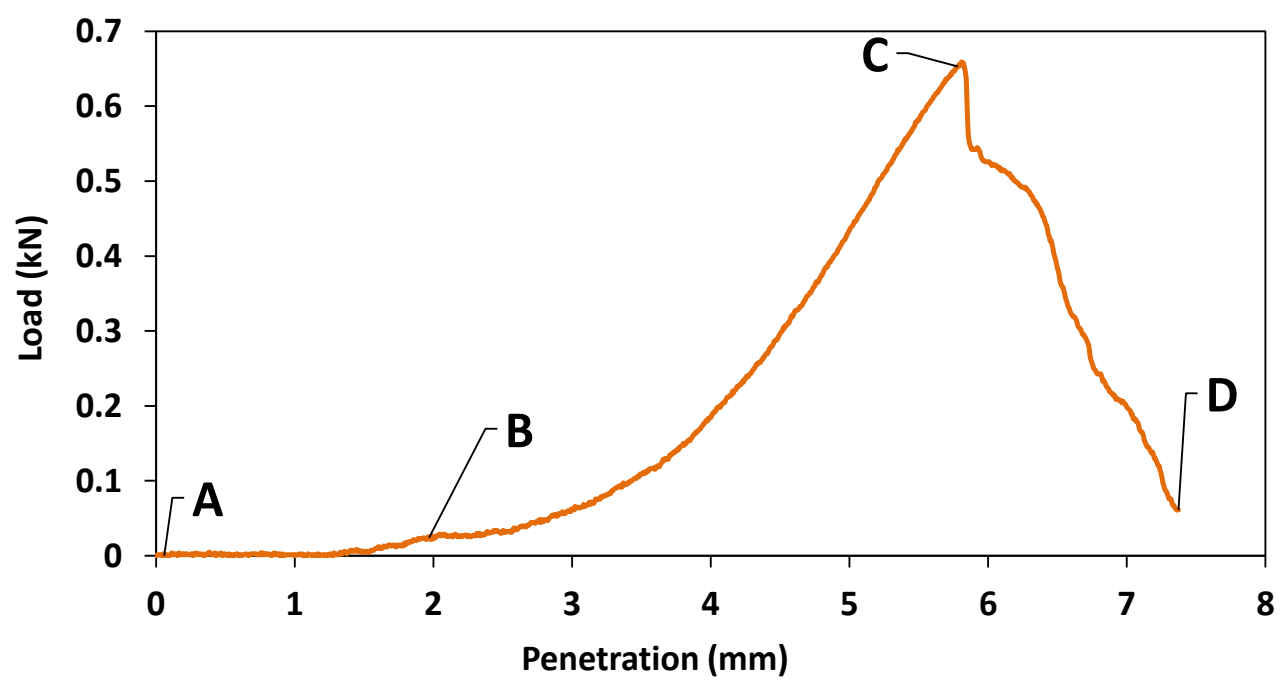

Figure 6. The load-penetration curve of the aluminum plate

In the honeycomb structure, the penetration and destruction shapes were distinct because of the lattice construction and adhesive bonding between adjacent walls of each cell. The destruction condition in unfilled honeycomb structure was a combination of cutting and crumpling. In foam filled honeycomb structure, some cells were cut and folded by the flat end of the penetrator (Figure 7).

According to the load-penetration curves of unfilled and foam filled honeycomb structures, more compressive force was required to penetrate the honeycomb structures filled with foam. Also, the higher the foam density, the greater the energy consumption to penetrate (Figure 8).

The penetration curve of the unfilled honeycomb structure is divided into six parts (Figure 9). As mentioned about the aluminum sheet diagram, the $\mathrm{AB}$ section indicates the penetrator establishment on the specimen. The BC part shows load carrying of the honeycomb. This situation represents a non-linear stiffness behavior of the honeycomb core. In $\mathrm{C}$ point, the first step of destruction is occurred. With the advancement of the penetration, a small amount of local 
folding of cell walls under the penetrator end is formed; which indicates the softening behavior between $\mathrm{C}$ and D. In DE distance, the curve is ascending and the propulsion of the penetrator combined with the tensile strength of the core and resistance of cell walls are increasing. The compressive load of the penetrator reaches its maximum at point E. At this point, the destruction of the adhesive connection between the cell walls surrounding the penetrator and crumpling of the cells begins. The honeycomb destruction zone is several times more than cross-sectional area of the penetrator, and the compressive force reaches to its maximum value at point F. Gradual slippage in EF distance resulted from the penetrator location and unsymmetrical resistance of honeycomb cells. At point $\mathrm{F}$, progressive extrusion of the penetrator from the honeycomb happens. The friction force makes a resistance of perforation. The experiment continues until point G. The distance FG shows the penetrator gradually passing through the honeycomb structure.
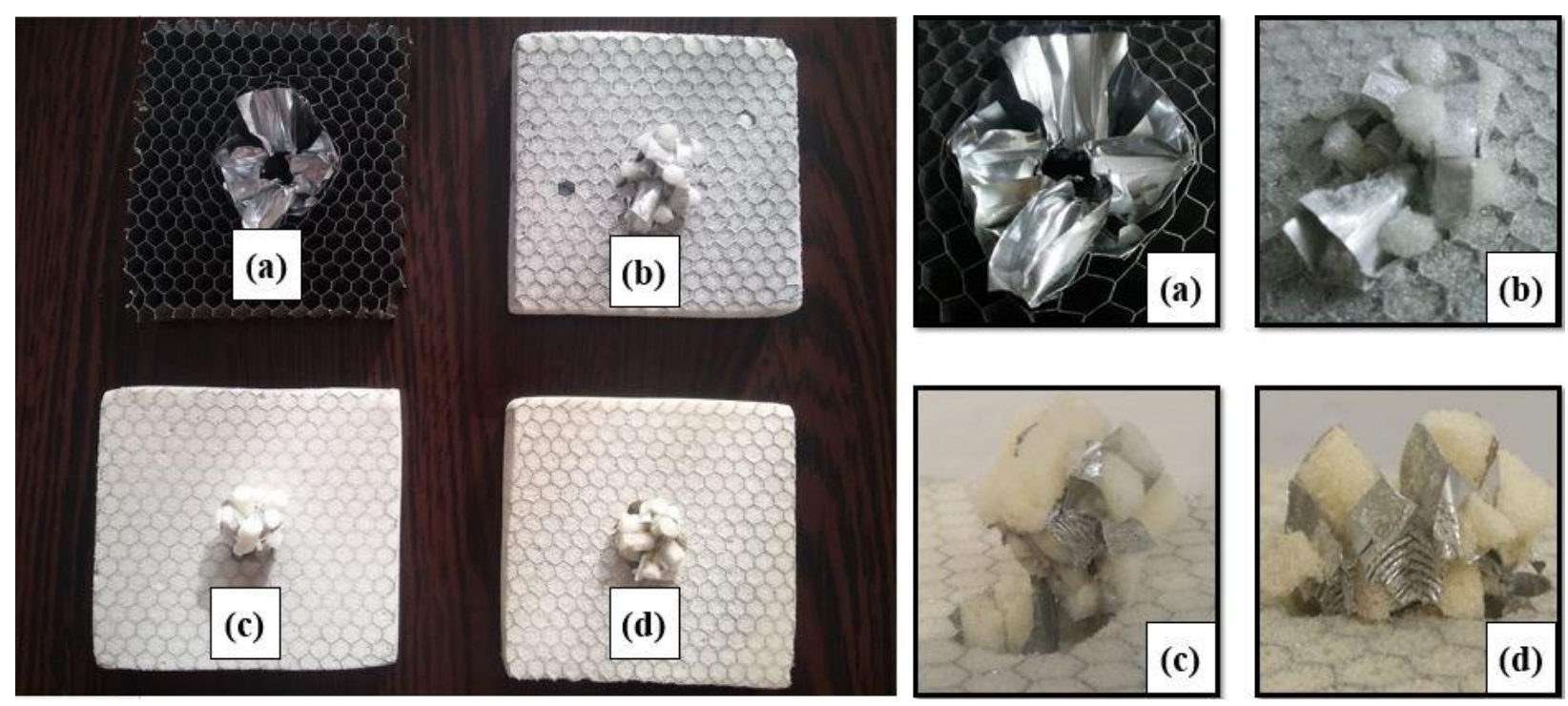

Figure 7. The backside of specimens after the quasi-static penetration (a) unfilled honeycomb structure (b) honeycomb structure filled with foam1 (c) honeycomb structure filled with foam2 (d) honeycomb structure filled with foam3 


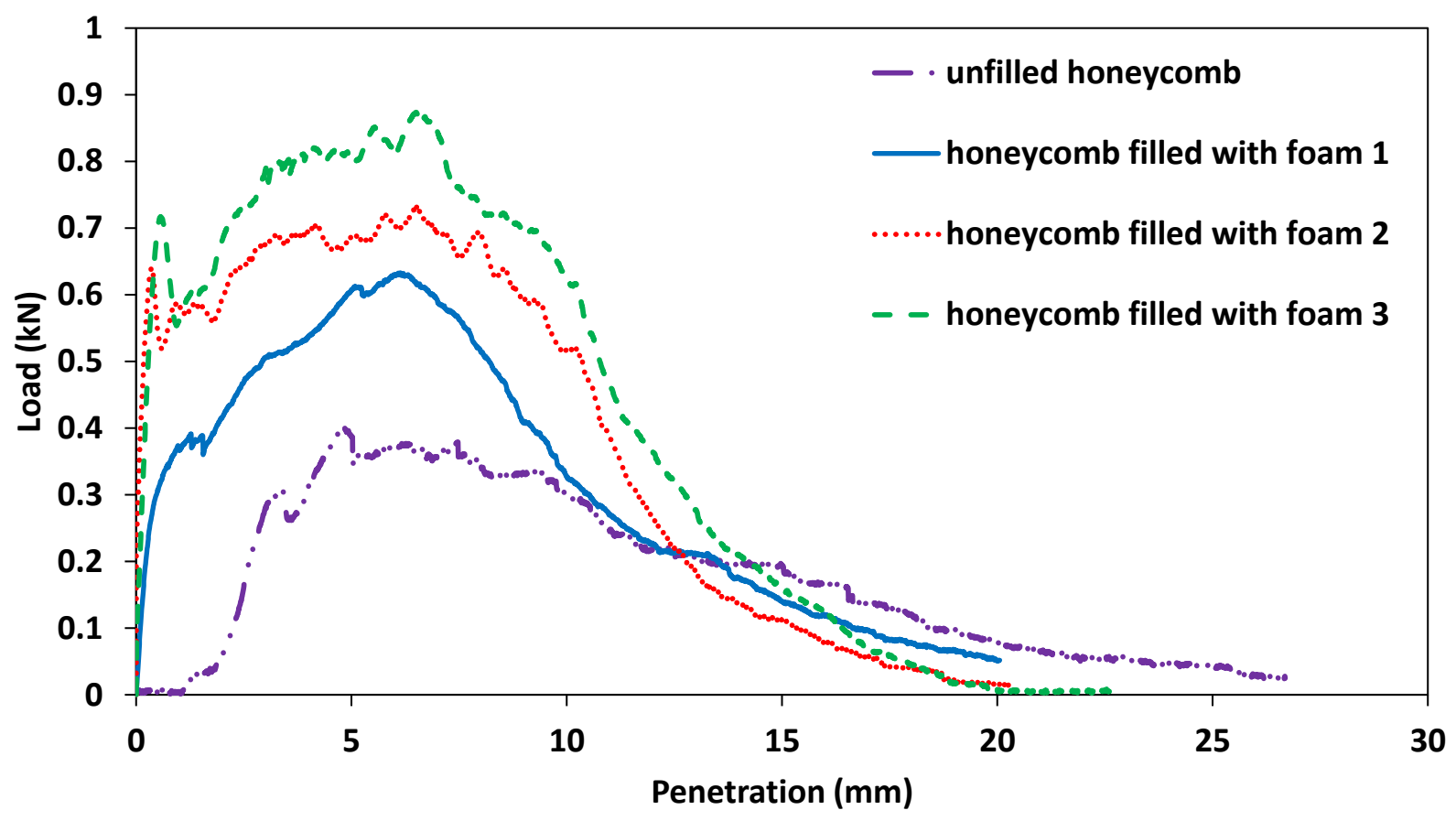

Figure 8. The load-penetration curves of the unfilled honeycomb structure and foam filled honeycomb structures

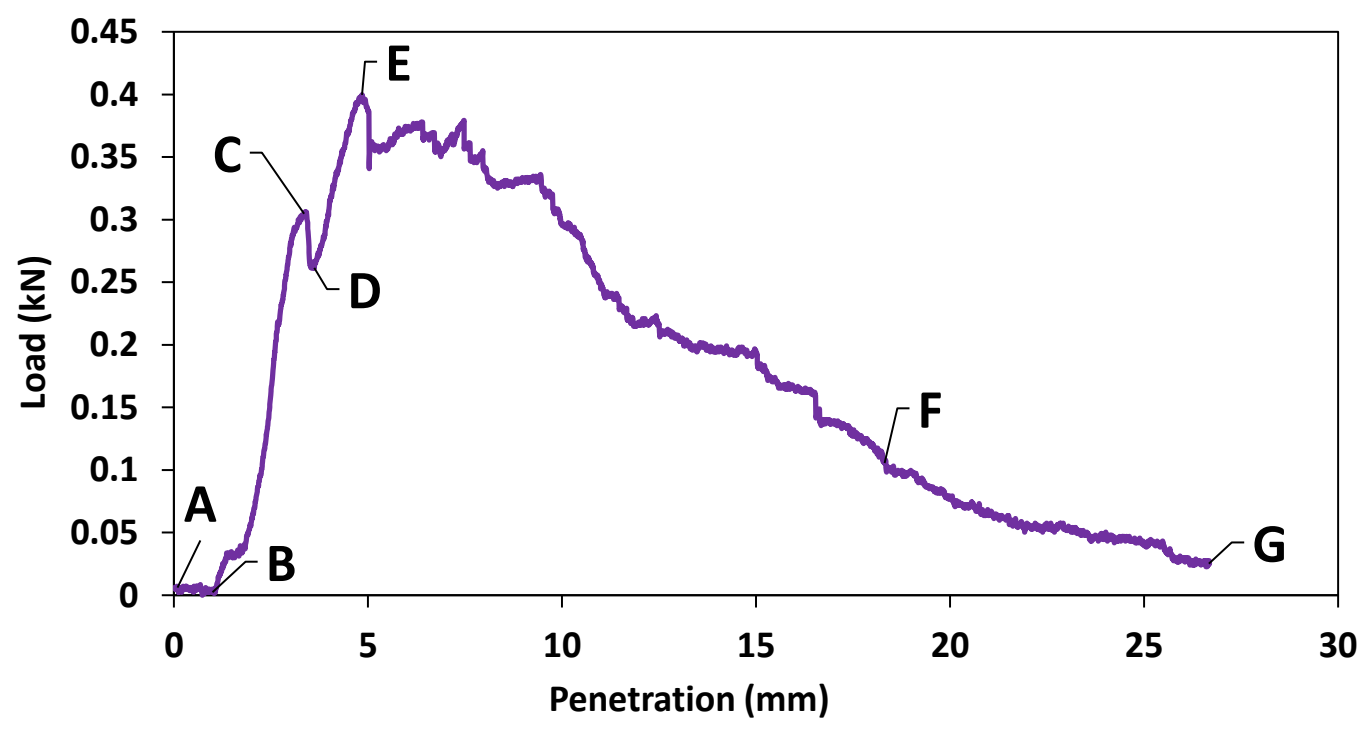

Figure 9. The load-penetration curve of the unfilled honeycomb structure 
In all sandwich panel structures, at the first step, the penetrator came into the top aluminum skin and a shear plug occurred. Then, it entered into the foam filled or unfilled aluminum honeycombs, and at the time of leaving the rear aluminum skin, a petal was created by driving out the crush destroyed core. Petals were formed near the edge of the penetrator. This destruction mode resulted from the bending moments in the underside of the specimens (Figure 10).

In load-penetration curves of all sandwich panels, in the first part (related to the penetration in the top skin), the amount of energy consumption for penetrating was equal in all specimens. But in the second part (related to the penetration in the core), the higher the foam density, the more energy was absorbed during the penetration of the striker in the specimen. This incident in the third part (related to the penetration in the rear skin), affected on penetration into the back skin of the structures. Therefore, the penetration into the back skin of sandwich panel filled with the third type of foam needed the most amount of energy (Figure 11).

The load-penetration curve of unfilled honeycomb sandwich panel has nine sections (Figure 12). The $\mathrm{AB}$ distance refers to penetrator seating on the sandwich panel. By moving forward of penetrator, the load-penetration curve will become concave showing reduction of the specimen stiffness in $\mathrm{BC}$ section. By increasing the force, the shear stress in the common border between the core and the face sheet will enhance which causes local damage of the resin bond and decreases the stiffness from point $\mathrm{C}$ to $\mathrm{D}$. The $\mathrm{CD}$ part represents the folding threshold of core in touch with penetrator. After point $\mathrm{D}$, the local separation of the face sheet from the sandwich panel as well as the penetrator propulsion results in plasticity, local elongation of honeycomb foil, crumple, and folding in the upper part of the honeycomb cell walls. At point E, a plug will be formed because there is maximum compressive load carrying capacity. After point E, the penetrator passes the top skin and comes into the core. In this stage, the force decreases and the 
removed plug attaches to the forehead of penetrator. The propulsion of penetrator with segregated plug creates folding in the upper side of the honeycomb core, under and surrounding of the penetrator. These factors reduce the local stiffness and cause the softening behavior between points $\mathrm{E}$ to $\mathrm{F}$. Honeycomb core resists against the penetrator and the adhesive bonding between its walls will fail at point $\mathrm{G}$ and the decrease of penetration load occur. Between points $\mathrm{G}$ to $\mathrm{H}$, failure in the adhesive bonds, folding and crumple of honeycomb walls increase. At point $\mathrm{H}$, the last part of the core is cut and removed. By this way, the stiffness of the sandwich panel will reduce considerably. The advancement of penetrator is combined with increasing the densification of core's cutting section and resistance of rear aluminum skin. The load-penetration curve will continue to point $\mathrm{I}$, at this point, the petals are formed in the back skin. Tending of core's cutting section to exit from the petals, causing curve expansion and point $\mathrm{J}$ and $\mathrm{K}$ will be created.
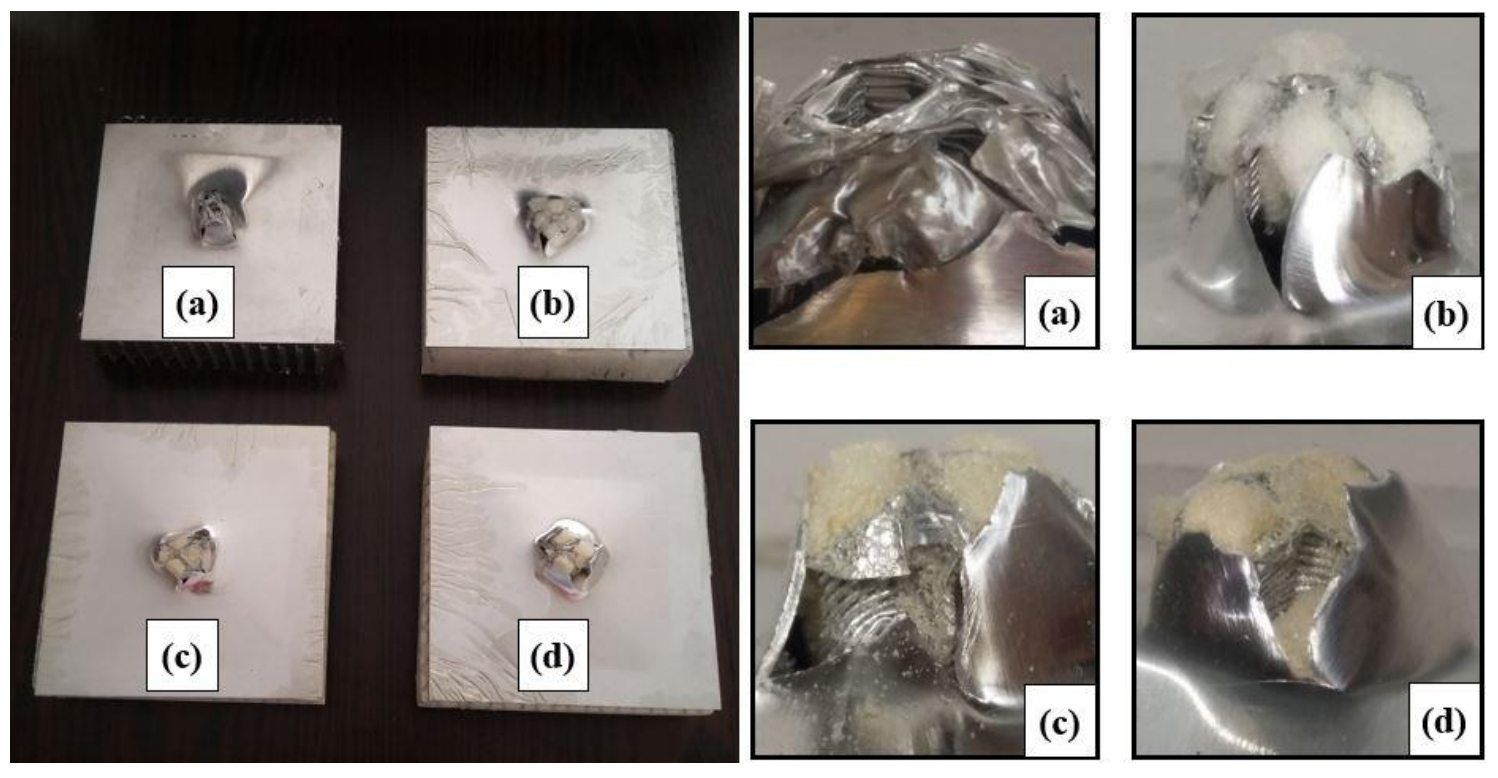

Figure 10. The backside of sandwich panels after the quasi-static penetration (a) sandwich panel with unfilled honeycomb core (b) sand wich panel filled with foaml (c) sandwich panel filled with foam2 (d) sand wich panel filled with foam3 


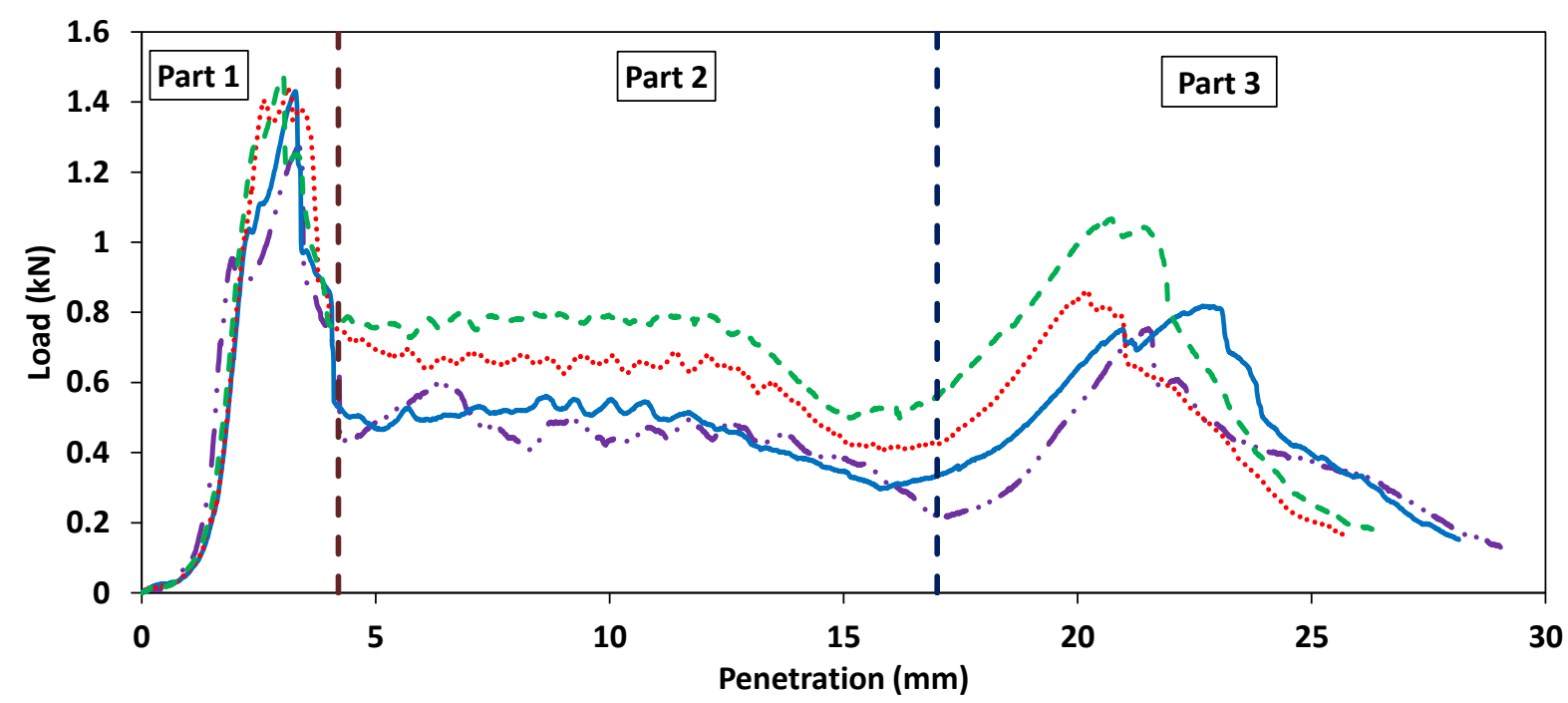

$\begin{array}{ll}\text { - } \cdot \text { sandwich panel with unfilled honeycomb } & \text { honeycomb sandwich panel filled with foam1 } \\ \cdots \cdot . . . \text { honeycomb sandwich panel filled with foam2 } & - \text { honeycomb sandwich panel filled with foam3 }\end{array}$

Figure 11. The load-penetration curves of the sandwich panels

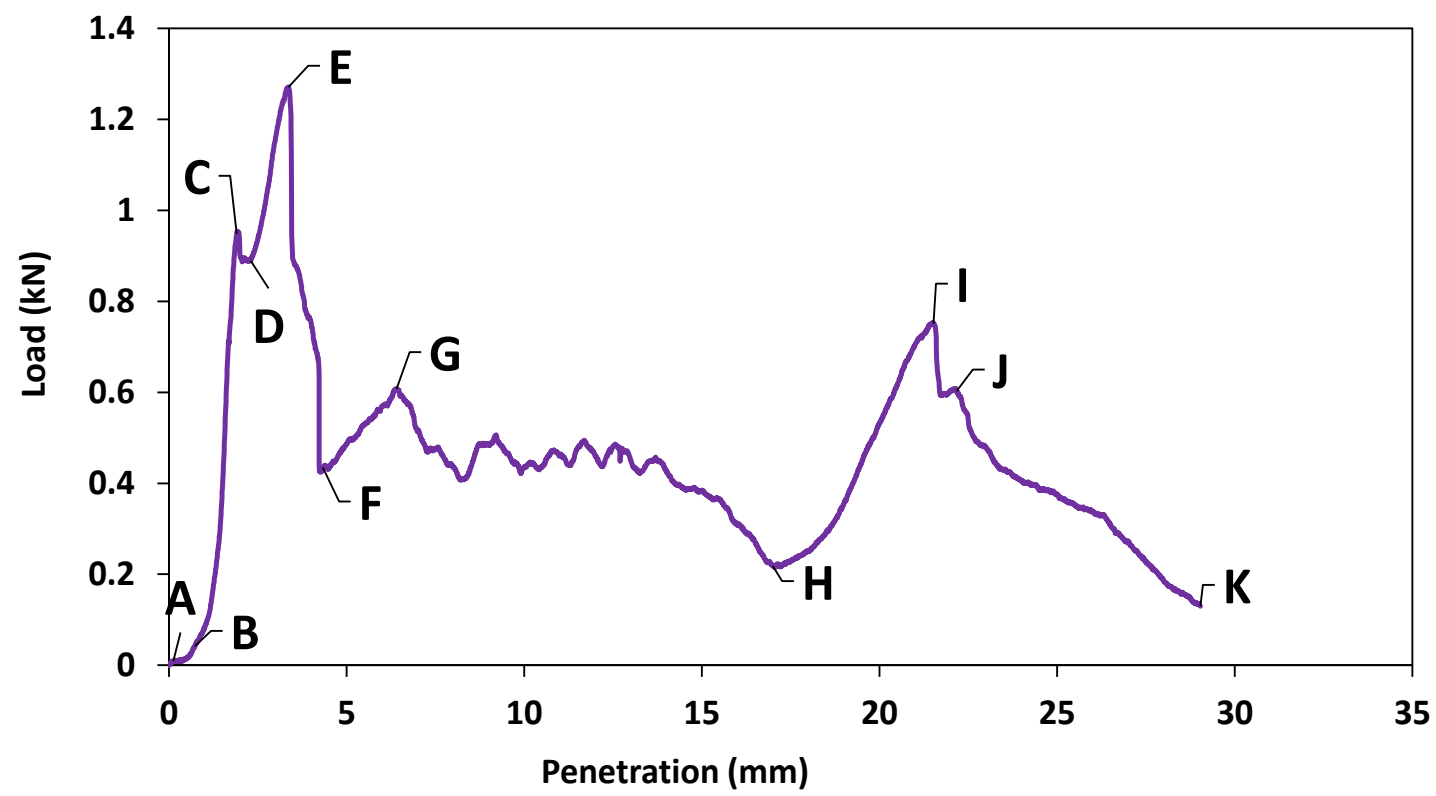

Figure 12. The load-penetration curve of the sandwich panel with unfilled honeycomb core 


\subsection{The effect of foam filling on the amount of absorbed energy in the honeycomb structure}

Figure 13 shows the absorbed energy of aluminum plate, unfilled honeycomb structure, honeycomb structure filled with foam1, 2 and 3 were 1.44, 4.69, 6.40, 7.94 and $9.36 \mathrm{~J}$, respectively. Comparing these values showed that the amount of the absorbed energy by the unfilled honeycomb structure is more than the absorbed energy by the aluminum plate and this increase was due to the lattice structure of them. Also, the absorbed energy by honeycomb structures with three types of foam was more than unfilled honeycomb structure. In fact, applying foam has increased the perforation strength of honeycomb structure. Owing to the absorbed energy histograms of the honeycomb structures filled with foam, it was observed that the honeycomb structure filled with the third type of foam $\left(137.13 \mathrm{~kg} / \mathrm{m}^{3}\right.$ density) had the most absorbed energy. The amount of the perforation absorbed energy of honeycombs filled with the first and second types of foams (foam density: 56.94 and $108.65 \mathrm{~kg} / \mathrm{m} 3$, respectively) was less than type three (Figure 13). 


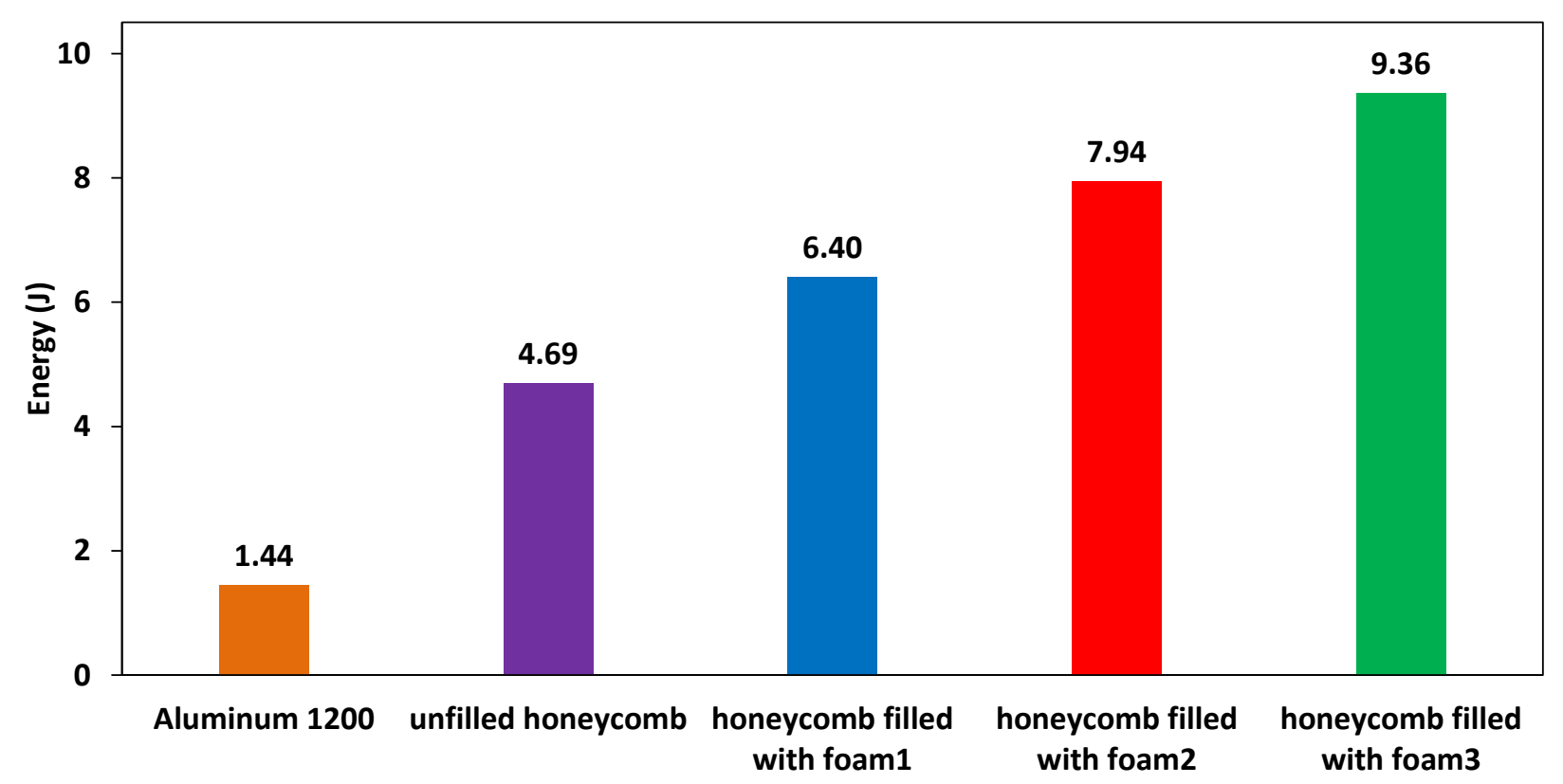

Figure 13. The comparison of the energy absorption related to each specimen

\subsection{The absorbed energy and specific energy absorption of the sandwich panels}

The absorbed energy of unfilled honeycomb sandwich panel, honeycomb sandwich panel filled with foam1, 2 and 3 were 11.41, 14.02, 15.19 and $18.00 \mathrm{~J}$, respectively. Obviously, the absorbed energy by the sandwich panels with foam filled honeycomb cores was more than unfilled ones. Consequently, the perforation strength of the sandwich panels was increased by polyurethane foams. The absorbed energy of foam filled sandwich panels would be enhanced by increasing the foam density, so the sandwich panels filled with the third type of foam $\left(137.13 \mathrm{~kg} / \mathrm{m}^{3}\right.$ density) had the most of the absorbed energy (Table 2).

The specific energy absorption (SEA) of each structure was calculated by measuring the weight and the absorbed energy of perforation. The SEA related to each structure is shown in Table 2. This parameter is $448,432,404$, and $473 \mathrm{~J} / \mathrm{kg}$ for unfilled honeycomb sandwich panel, honeycomb sand wich panel filled with foam1, 2 and 3, respectively. 
The SEA of the sandwich panel filled with the foam type 3 was more than the other structures. This indicates that the strength to weight ratio of the sandwich panel filled with the foam type 3 is appropriate to use as the energy absorbing structure in perforation loading. The SEA of the sandwich panels filled with the foam types 1 and 2 are less than the sandwich panel with the unfilled honeycomb core. Concentrating on SAE values show that although foam filling of panels enhances their energy absorption capacity, it has not a remarkable effect on the amount of SAE in sandwich panels filled with the foam1 and foam2, because heavier foam enhances both the mass of the panel and the absorbed energy. Therefore, SAE which is the ratio of these two parameters remains roughly unchanged $\left(S A E=\frac{E_{a}}{W_{s}}\right.$ wich $E_{a}$ and $W_{s}$ are energy absorption and weight of structure, respectively). Since these parameters change at the same time, the effect of one of them may be more than the other. In the case of sandwich panels filled with foaml and foam2, a reduction in SEA was seen which shows the increase in absorbed energy was not as much as the increase in mass of the samples, therefore, the amount of SEA reduces in comparison with the unfilled sandwich panels. In addition, it is worth mentioning that this result is in line with some other reports in previous studies [25, 36].

Table 2. Experimental values of absorbed energy and specific energy absorption of sandwich panels

\begin{tabular}{cccc}
\hline Specimens & Mass (g) & Absorbed energy (J) & SEA (J/kg) \\
\hline Unfilled sandwich panel & 25.48 & 11.44 & 448 \\
\hline Sand wich panel filled with foam1 & 32.44 & 14.02 & 432 \\
\hline Sand wich panel filled with foam2 & 37.58 & 15.19 & 404 \\
\hline Sand wich panel filled with foam3 & 38.06 & 18.00 & 473 \\
\hline
\end{tabular}




\subsection{The effect of interaction among aluminum plate, honeycomb structure and the polyurethane foam on absorbed ene rgy in the sandwich panel}

The sandwich panel is made from two aluminum plates, as well as unfilled and polymer foam filled aluminum honeycomb core. As shown in Figure 14, the penetration in the sandwich structure occurs in three steps caused by the interaction effects. In the first step, which the indenter perforates the upper skin, the interaction effects I, II and III makes the indenter penetration into sandwich panel more difficult than the individual aluminum sheet. In fact, these three interaction effects have increased the stiffness and strength of the sandwich structures. Also, there is an interaction between the indenter and the upper skin which leads to penetration.

In the second step, the indenter enters into the core and since the honeycomb core is filled with foam, the interaction effects II and III makes the indenter penetration harder; a large amount of the indenter kinetic energy is reduced due to interaction effect II. Here, there is also an interaction between the indenter and the core, which results in core folding.

In the third step, the indenter reaches the rear skin, as it causes debonding between the rear skin and the core, the interaction effect III has no noticeable yield. In this section, the interaction effect IV is established between the indenter and rear skin. Finally, the indenter full penetration has occurred.

The results show that the absorbed energy by unfilled honeycomb core sand wich panel was $34 \%$ higher than the summation of two aluminum plates and honeycomb structure individually (Figure 15). The absorbed energy by the honeycomb core sandwich panel filled with foam types 1, 2 and 3 are $35 \%, 29 \%$, and $32 \%$ higher than the summation of two aluminum plates and honeycomb structure filled with the foam types 1, 2 and 3, respectively. As shown in Figure 15, 
the summation of individual components absorbed energy (two aluminum plates and honeycomb structure filled with three types of foams) is lower than for the entire similar sandwich panel, because the honeycomb supports the skins and delays the collapse of them and behaves as an integrated structure. As shown in Figure 15, by increasing the foam2 density, the amount of interaction effect does not increase, and is approximately equal to the sandwich panel filled with foam1. This can happen for two reasons: 1) the poly unit of foam2 is different from two other foams. 2) The interaction effect of this foam with the honeycomb cell walls decreases the interaction effect of whole structure. In fact, this foam cannot create an appropriate adhesion between itself and honeycomb cell walls; so, it has not been able to increase the strength of the walls under penetration test and energy absorption does not increase to the desired extent.

Also, Figure 15 showed the calculation of interaction effect for each sandwich panel. The interaction effect in unfilled sandwich panel was related to the interaction between the facings and honeycomb core. The interaction effect in the foam filled sandwich panels was re lated to the interaction between the cell walls of honeycomb structure and the foam, as well as the interaction between the facings and the foam. The polyurethane foam increased the strength of the honeycomb structure. In addition, the interaction between aluminum plate and honeycomb cores filled with foam enhanced the energy absorption considerably; which indicated the superiority of sandwich structures than conventional structures. 


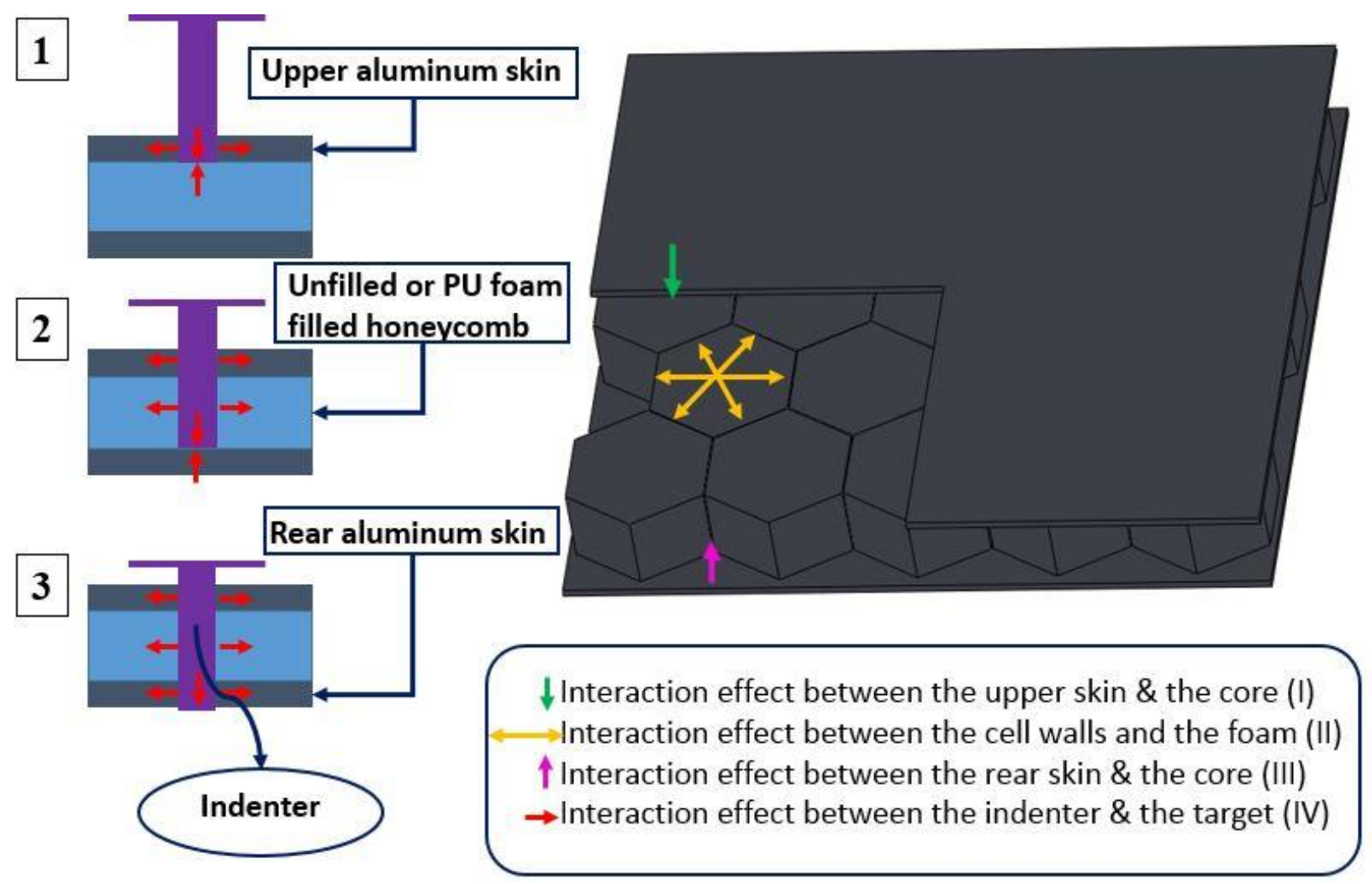

Figure 14. The schematic drawing of interaction and penetration mechanisms

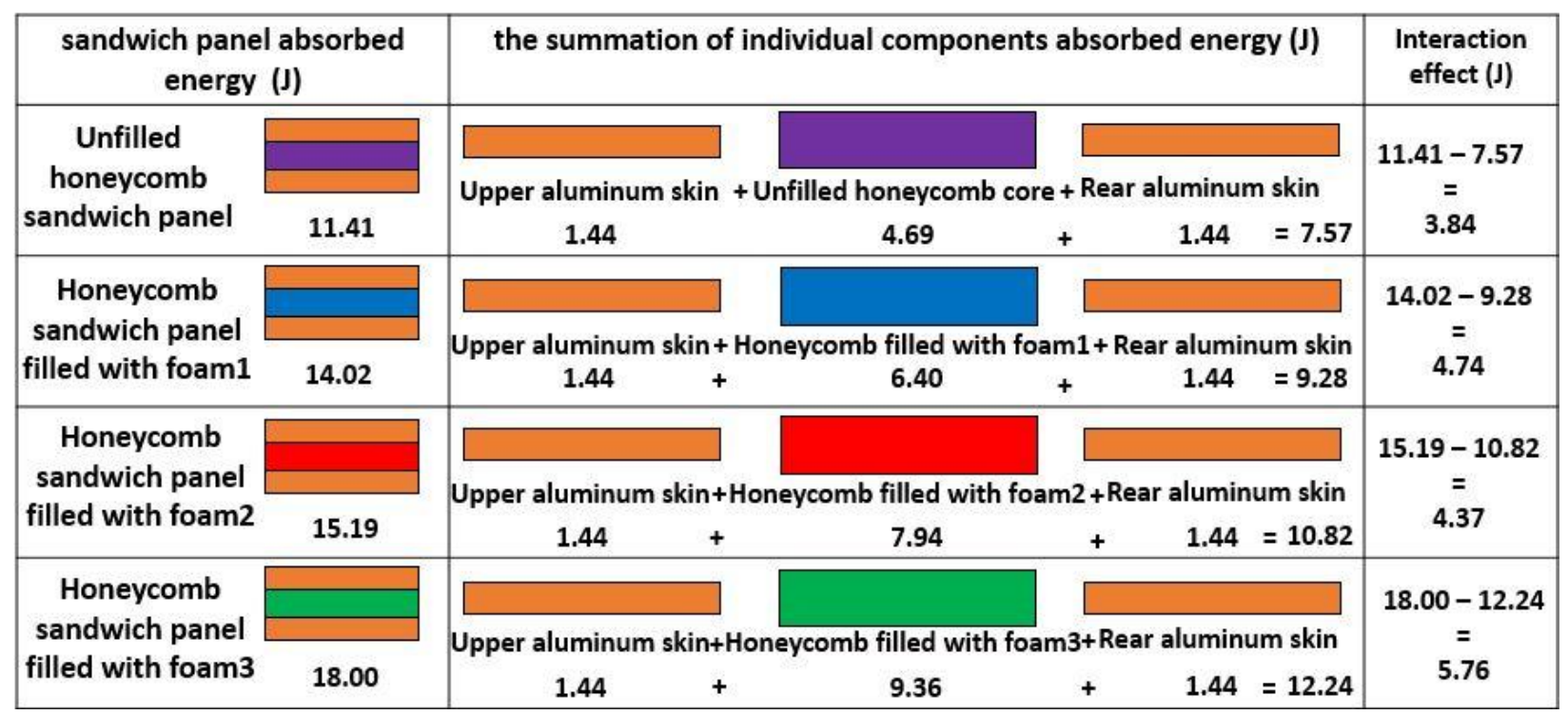

Figure 15. The absorbed energy comparison chart related to the sandwich panels versus their individual components 


\subsection{The effect of foam filling on the destruction area and folding of the honeycomb core}

Honeycomb structure has a specific lattice building that the destruction area after penetration will be larger than the indenter diameter and this difference made it inefficient for using in some industries. As seen in Figure 16, the damage area in the unfilled honeycomb structure is approximately 4 times wider than the indenter size but the presence of foam in the filled honeycomb remarkably decrease the damage area by lessening crumpled cell walls. In addition, the remaining cells around the damage area in the unfilled structure lose their hexagonal shape, but in the filled one, the cells have completely maintained their own shape (Figure 16).

Also, the position of the indenter may affect the results of the penetration test due to the indenter's cross section and the honeycomb's unit cell and also it is obvious by decreasing the unit cell dimension or increasing the indenter's diameter this difference will be insignificant. So, in this paper, the dimensions of the specimens and the indenter's position were carefully selected in a way that the central position of the indenter is placed on the center of the honeycomb cell, which is clearly shown in Figure 17 a. In this way, the effect of indenter position on the penetration results is removed and all the tests were conducted in the same condition.

When the central position of the indenter is placed on the center of the honeycomb cell, the rest of the penetrator surface in relation to the target can be set to three modes (Figure 18):

1- If a part of the indenter is placed between the adhesive bonding of two walls, the penetrator will tear the wall of neighbor cell and increase the damage area.

2- If a part of the indenter is placed in the node of three walls, one of the involved cells in the node will be torn and enhance the damage area. 
3. If the penetrator is placed on a whole cell (the best form of penetrator placement), it will create folding in the cell and made less destruction area than the previous positions.

In the quasi-static penetration test, due to concentrated loading and importance of penetrator position, the folding of the cells under loading is not completely performed in the process of destruction, because the cutting of cell walls occurs earlier.

In order to investigate the effect of foam on the number of folds, the sandwich panel filled with foam 3 (the best energy absorber in this study) and the unfilled sandwich structure were put under distributed loading (Figure 19).

Distributed loading tests were performed using a Universal Testing Machine (model WDW$300 \mathrm{E})$ at displacement rate of $2 \mathrm{~mm} / \mathrm{min}$. Figure 20 shows the stress-strain curves for unfilled and foam3 filled sandwich structure under distributed loading. These curves can be divided into three parts, including the elastic regime, crushing regime and densification regime.

In the elastic regime, the stress-strain curve is primarily linear, but becomes non-linear at the later stages owing to elastic buckling of the cells. When the local stresses in the cell walls go beyond the yield threshold, the elastic regime ends and the core collapses. This point is characterized by a peak stress that is followed by a short softening regime preceding the crushing regime. In the crushing regime, the cell walls are gradually folded. The crushing regime continues over a wide range of strains until the entire structure is folded and the stress growths as the folded structure is densified. The densification stress $\left(\sigma_{d}\right)$ and the densification strain $\left(\varepsilon_{d}\right)$ related to two panels which were summarized in Table 3.

According to Table 3, the number of folding in the foam 3 filled sandwich panel is three values more than the unfilled one, and this increase in folding has caused the absorbed energy of the 
foam 3 filled sandwich panel to be $92 \%$ more than the unfilled one, while the densification strain of two structures is similar.

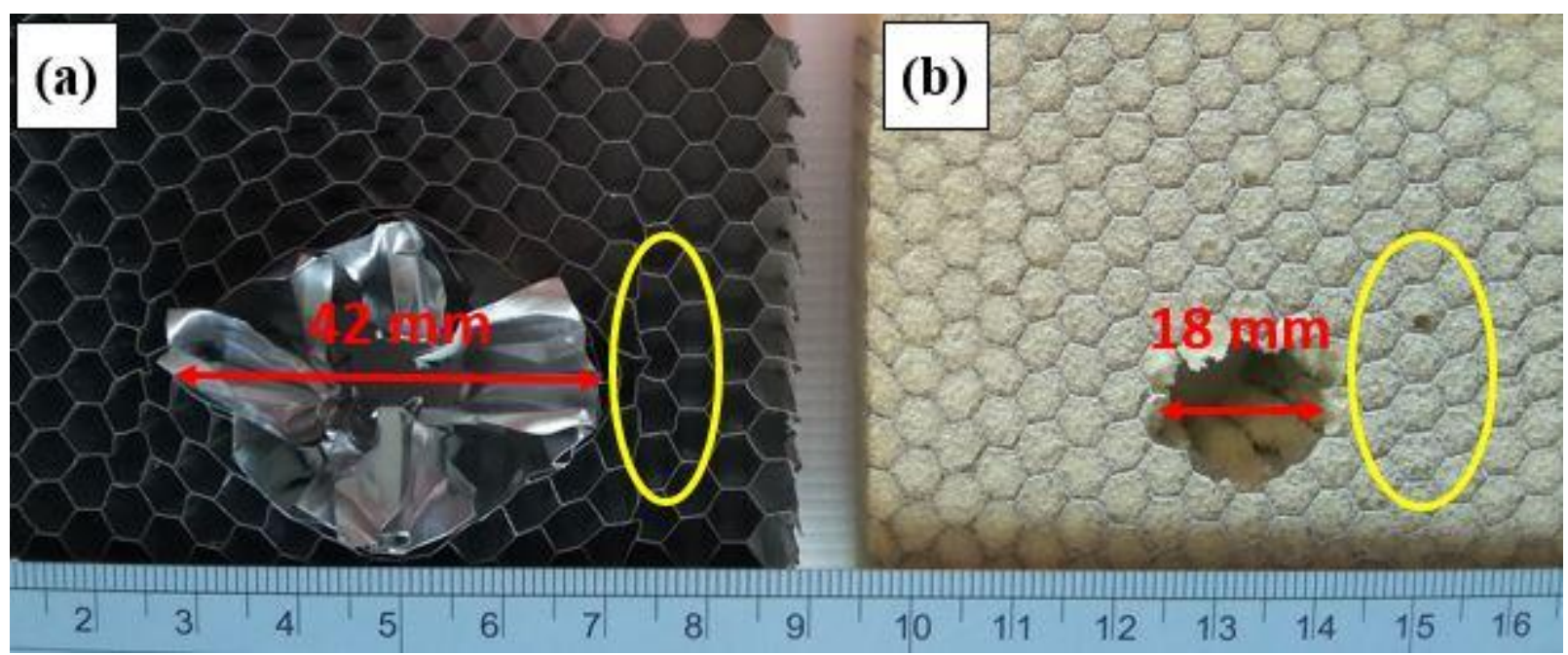

Figure 16. Damage area (a) unfilled honeycomb structure (b) foam3 filled honeycomb structure
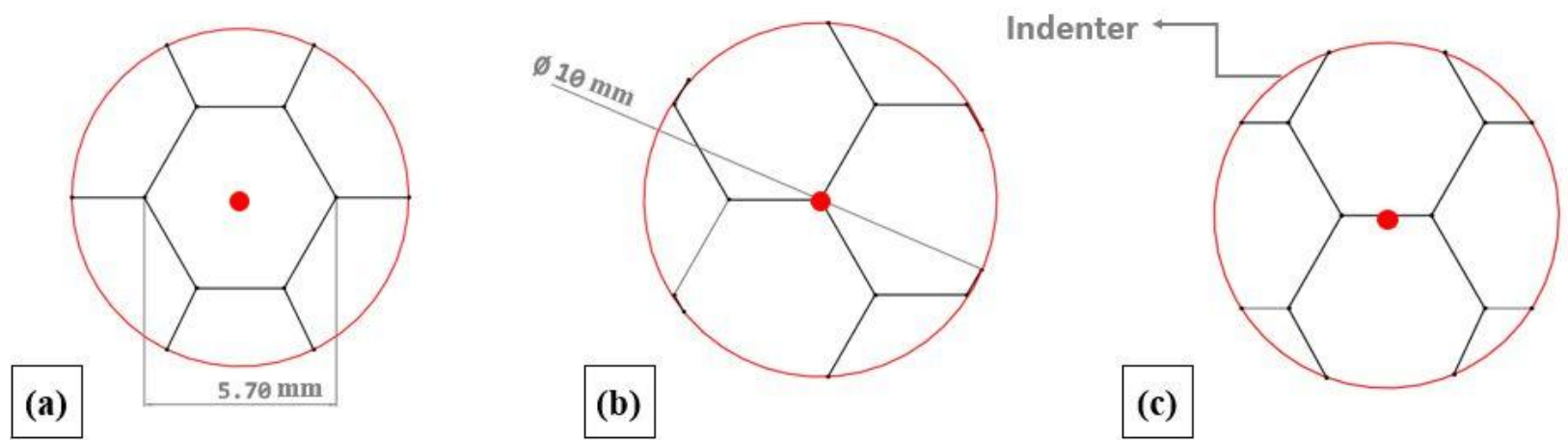

Figure 17. The positions of the center point of indenter on the honeycomb cell 


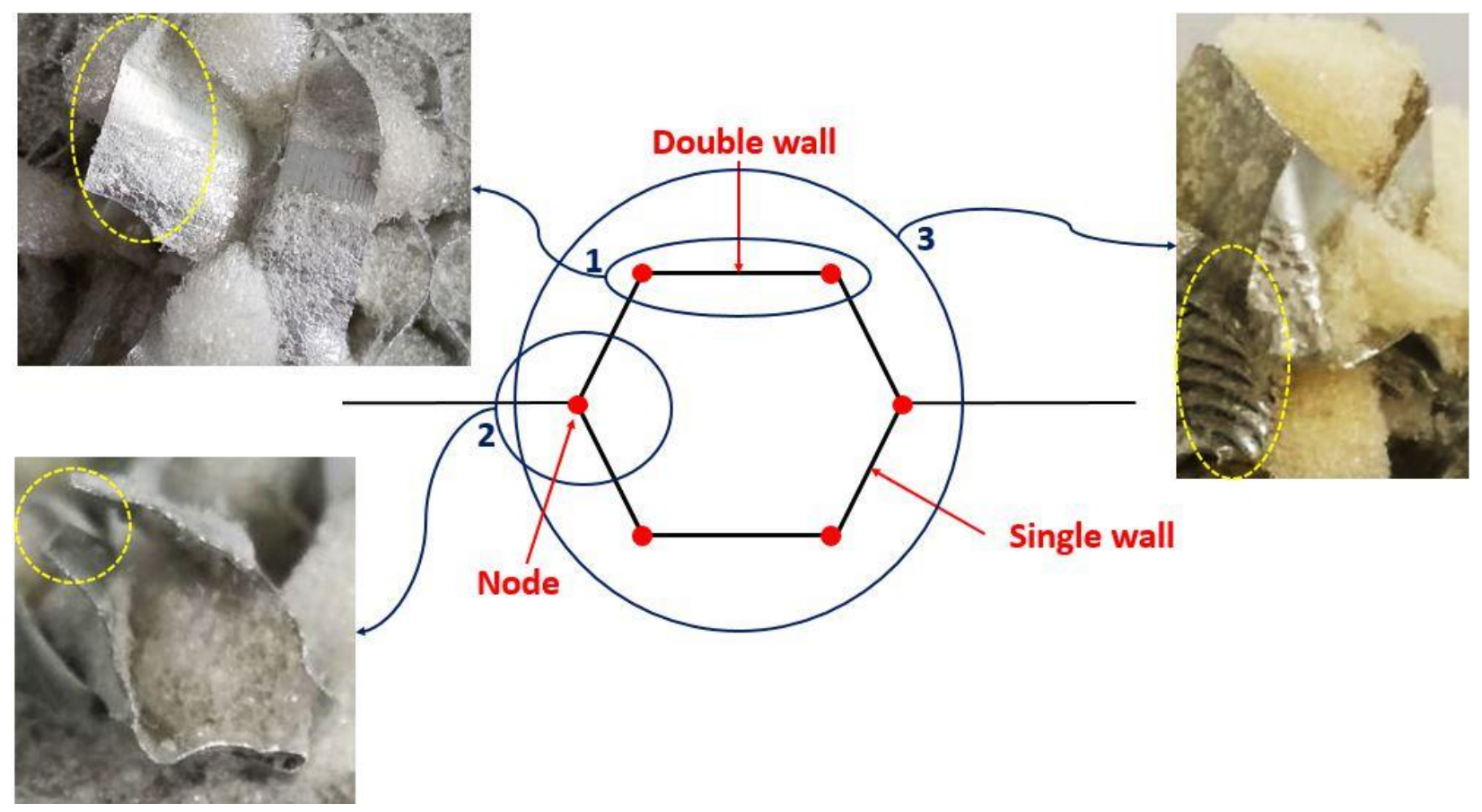

Figure 18. The positions of non-centered point of indenter on the honeycomb cell

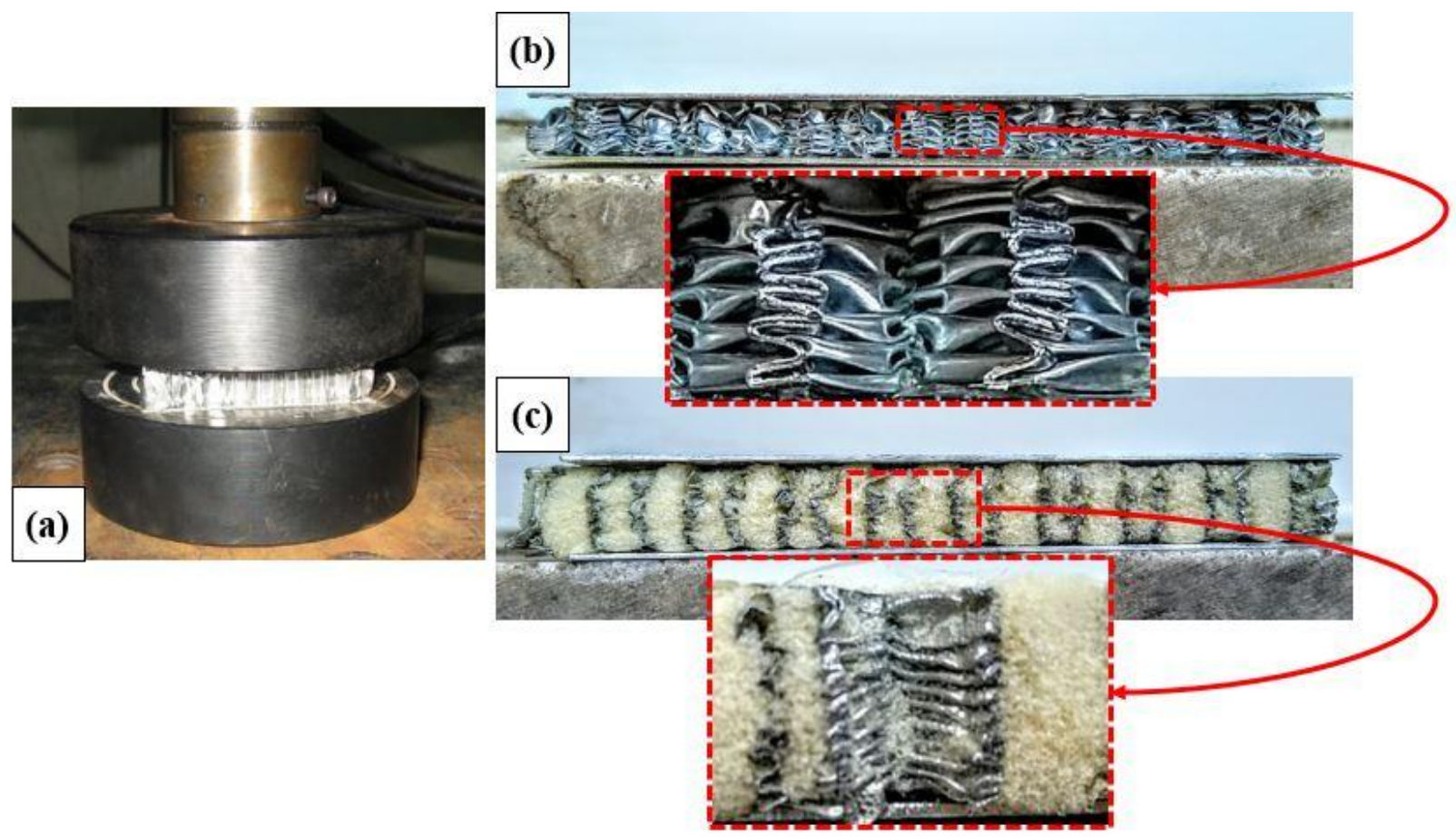

Figure 19. (a) The sandwich structure under distributed loading (b) the folding of unfilled sandwich panel(c) the folding of foam3 filled sandwich panel 


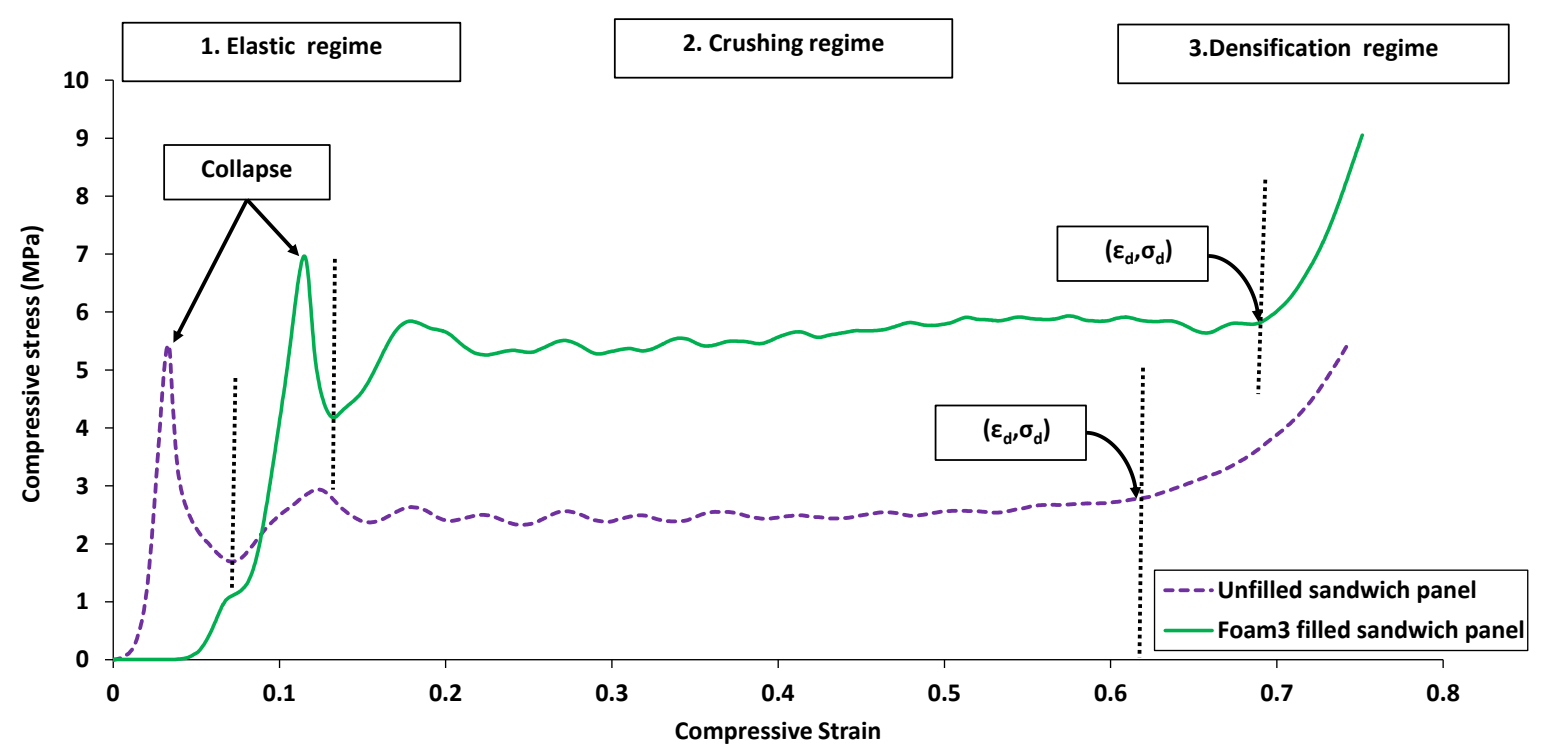

Figure 20. The stress-strain curve related to unfilled and foam 3 filled sandwich panel under distributed loading

Table 3. Comparison of unfilled and foam3 filled sandwich panel under distributed loading

\begin{tabular}{cccccc}
\hline specimens & $\boldsymbol{\varepsilon}_{\mathbf{d}}$ & $\boldsymbol{\sigma}_{\mathbf{d}}(\mathbf{M P a})$ & $\begin{array}{c}\text { Number of } \\
\text { folds }\end{array}$ & $\begin{array}{c}\text { Absorbed } \\
\text { energy }(\mathbf{J})\end{array}$ & $\begin{array}{c}\text { SEA } \\
(\mathbf{J} / \mathbf{k g})\end{array}$ \\
\hline Unfilled sandwich panel & 0.62 & 2.79 & 6.5 & 224 & 8778 \\
\hline Foam3 filled sandwich panel & 0.69 & 5.83 & 9.5 & 430 & 11291 \\
\hline
\end{tabular}

\section{Conclusions}

In this paper, the quasi-static perforation of sandwich panels with unfilled and polyurethane foam filled honeycomb core were studied. Also, the shape of destruction and the absorbed energy of the aluminum plate, unfilled honeycomb structure, honeycomb structure filled with three types of foams, sandwich panels with unfilled and polymer foam filled honeycomb core were obtained when they are subjected to quasi-static penetration. The effect of interaction among aluminum 
plate, honeycomb structure and the polyurethane foam on absorbed energy in the sandwich panel, as well as, the effect of filling foam on the destruction area and folding of the honeycomb core were investigated.

The results show that the absorbed energy by unfilled honeycomb core sandwich panel is $34 \%$ higher than the summation of two aluminum plates and unfilled honeycomb structure individually. The absorbed energy by honeycomb core sandwich panel filled with foam types 1 , 2 and 3 are $35 \%, 29 \%$, and $32 \%$ higher than the summation of two aluminum plates and honeycomb structure filled with the foam types 1,2 and 3 , respectively. Comparing the three types of foam filled sandwich panels with unfilled type, indicates that the absorbed energy of the sandwich panels filled with the foam types 1, 2 and 3 are $23 \%, 33 \%$, and $58 \%$ more than unfilled ones, respectively.

The presence of foam in the filled honeycomb has reduced its damage area to less than half of unfilled damage area. Also, the results show that the damage area in the unfilled honeycomb structure is approximately 4 times wider than the indenter size.

For investigating the effect of foam on the number of folds, the sandwich panel filled with foam3 $\left(137.13 \mathrm{~kg} / \mathrm{m}^{3}\right.$, the best energy absorber in this study) and the unfilled sandwich structure were put under distributed loading. The sandwich panel filled with foam3 increases absorbed energy of proportional to unfilled sandwich panel by $92 \%$.

Here, it is shown that the combination of honeycomb and foam together eventuate to produce structures with higher effective properties and resistances. Also, using foam with higher density increases the absorbed energy and structural efficiency in quasi-static penetration. Thus, 
polyurethane foam filled honeycomb sandwich structures have the potential to be used as efficient energy-absorbing structures in many applications.

\section{References}

[1] S. Abrate, Impact on laminated composite materials, Applied mechanics reviews, 44 (1991) $155-190$.

[2] A. Niknejad, G. Liaghat, Experimental study of Poly-orthan foam filler on hexagonal honeycomb structure behavior under axial load with constant rate, in: 10th Iran Aerospace conference (AERO2011), Tarbiat Modarres University, 2011.

[3] A.A. Nia, M. Sadeghi, An experimental investigation on the effect of strain rate on the behaviour of bare and foam-filled aluminium honeycombs, Materials \& Design (1980-2015), 52 (2013) 748-756.

[4] W. Goldsmith, D.L. Louie, Axial perforation of aluminum honeycombs by projectiles, International Journal of Solids and Structures, 32 (1995) 1017-1046.

[5] S.A. Galehdari, M. Kadkhodayan, S. Hadidi-Moud, Analytical, experimental and numerical study of a graded honeycomb structure under in-plane impact load with low velocity, International journal of crashworthiness, 20 (2015) 387-400.

[6] S.D. Papka, S. Kyriakides, In-plane compressive response and crushing of honeycomb, Journal of the Mechanics and Physics of Solids, 42 (1994) 1499-1532.

[7] S.D. Papka, S. Kyriakides, In-plane crushing of a polycarbonate honeycomb, International Journal of Solids and Structures, 35 (1998) 239-267.

[8] A.A. Nia, S. Razavi, G. Majzoobi, Ballistic limit determination of aluminum honeycombsexperimental study, Materials Science and Engineering: A, 488 (2008) 273-280. 
[9] G.H. Liaghat, A.A. Nia, H.R. Daghyani, M. Sadighi, Ballistic limit evaluation for impact of cylindrical projectiles on honeycomb panels, Thin-Walled Structures, 48 (2010) 55-61.

[10] E. Wu, W.-S. Jiang, Axial crush of metallic honeycombs, International Journal of Impact Engineering, 19 (1997) 439-456.

[11] H. Zhao, G. Gary, Crushing behaviour of aluminium honeycombs under impact loading, International Journal of Impact Engineering, 21 (1998) 827-836.

[12] S. Deqiang, Z. Weihong, W. Yanbin, Mean out-of-plane dynamic plateau stresses of hexagonal honeycomb cores under impact loadings, Composite Structures, 92 (2010) 2609-2621. [13] S. Xu, J.H. Beynon, D. Ruan, T. Yu, Strength enhancement of aluminium honeycombs caused by entrapped air under dynamic out-of-plane compression, International journal of impact engineering, 47 (2012) 1-13.

[14] S. Xu, J.H. Beynon, D. Ruan, G. Lu, Experimental study of the out-of-plane dynamic compression of hexagonal honeycombs, Composite Structures, 94 (2012) 2326-2336.

[15] F. Hassanpour Roudbeneh, G. Liaghat, H. Sabouri, H. Hadavinia, Experimental investigation of impact loading on honeycomb sandwich panels filled with foam, International Journal of Crashworthiness, (2018) 1-12.

[16] A. Petras, Design of sandwich structures, in, University of Cambridge, 1999.

[17] G. Lu, T. Yu, Energy absorption of structures and materials, Elsevier, 2003.

[18] H. Wen, T. Reddy, S. Reid, P. Soden, Indentation, penetration and perforation of composite laminate and sandwich panels under quasi-static and projectile loading, in: Key Engineering Materials, Trans Tech Publ, 1998, pp. 501-552.

[19] M.H. Türk, M.S.H. Fatt, Localized damage response of composite sandwich plates, Composites Part B: Engineering, 30 (1999) 157-165. 
[20] É. Lolive, J.-M. Berthelot, Non-linear behaviour of foam cores and sandwich materials, part 2: indentation and three-point bending, Journal of Sandwich Structures \& Materials, 4 (2002) 297-352.

[21] E. Flores-Johnson, Q. Li, Experimental study of the indentation of sandwich panels with carbon fibre-reinforced polymer face sheets and polymeric foam core, Composites Part B: Engineering, 42 (2011) 1212-1219.

[22] J.E. Williamson, Response mechanisms in the impact of graphite/epoxy honeycomb sandwich panels, in, Massachusetts Institute of Technology, 1991.

[23] D. Ruan, G. Lu, Y.C. Wong, Quasi-static indentation tests on aluminium foam sandwich panels, Composite Structures, 92 (2010) 2039-2046.

[24] K. Arslan, R. Gunes, M.K. Apalak, J. Reddy, Experimental tests and numerical modeling of ballistic impact on honeycomb sandwich structures reinforced by functionally graded plates, Journal of Composite Materials, 51 (2017) 4009-4028.

[25] A.A. Nia, M. Sadeghi, The effects of foam filling on compressive response of hexagonal cell aluminum honeycombs under axial loading-experimental study, Materials \& Design, 31 (2010) 1216-1230.

[26] S. Santosa, T. Wierzbicki, Crash behavior of box columns filled with aluminum honeycomb or foam, Computers \& Structures, 68 (1998) 343-367.

[27] G. Caserta, U. Galvanetto, L. Iannucci, Static and dynamic energy absorption of aluminum honeycombs and polymeric foams composites, Mechanics of Advanced Materials and Structures, 17 (2010) 366-376.

[28] H. Demir, M. Sipahioğlu, D. Balköse, S. Ülkü, Effect of additives on flexible PVC foam formation, journal of materials processing technology, 195 (2008) 144-153. 
[29] T. Reddy, R. Wall, Axial compression of foam-filled thin-walled circular tubes, International Journal of Impact Engineering, 7 (1988) 151-166.

[30] S. Reid, T. Reddy, M. Gray, Static and dynamic axial crushing of foam-filled sheet metal tubes, International Journal of Mechanical Sciences, 28 (1986) 295-322.

[31] R. Mohmmed, F. Zhang, B. Sun, B. Gu, Static and low-velocity impact on mechanical behaviors of foam sandwiched composites with different ply angles face sheets, Journal of Composite Materials, 48 (2014) 1173-1188.

[32] ASTM Standard E8M-04, Standard test methods for tension testing of metallic materials. West Conshohocken (PA): AS TM International, 2004.

[33] N. Abdolrahim, G. Liaghat, H.A. Askari, Experimental study of low velocity impact on Sandwich panels with honeycomb core and Comparison with the FEM results, A A, 49 (2008) 45.

[34] ASTM D1622 Standard test method for apparent density of rigid cellular plastics, 2004.

[35] ASTM D1621 Standard test method for compressive properties of rigid cellular plastics, 2004.

[36] H. Mozafari, S. Khatami, H. Molatefi, V. Crupi, G. Epasto, E. Guglielmino, Finite element analysis of foam-filled honeycomb structures under impact loading and crashworthiness design, International journal of crashworthiness, 21 (2016) 148-160. 